OECDpublishing

\title{
MEASURING CLOUD SERVICES USE BY BUSINESSES
}

OECD DIGITAL ECONOMY PAPERS

January 2021 No. 304 
This paper was approved and declassified by the Committee on Digital Economy Policy on 19/11/20 and prepared for publication by the OECD Secretariat.

Note to Delegations:

This document is also available on O.N.E under the reference code:

DSTI/CDEP/MADE(2019)1/FINAL

This document, as well as any data and any map included herein, are without prejudice to the status of or sovereignty over any territory, to the delimitation of international frontiers and boundaries and to the name of any territory, city or area.

The statistical data for Israel are supplied by and under the responsibility of the relevant Israeli authorities or third party. The use of such data by the OECD is without prejudice to the status of the Golan Heights, East Jerusalem and Israeli settlements in the West Bank under the terms of international law.

(C) $\operatorname{OECD}(2021)$

The use of this work, whether digital or print, is governed by the Terms and Conditions to be found at http://www.oecd.org/termsandconditions. 


\section{Table of contents}

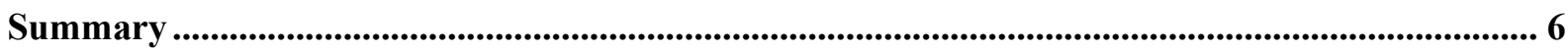

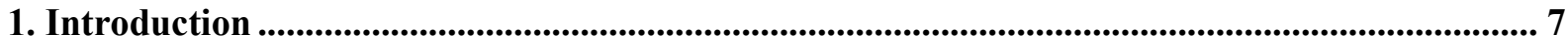

2. Cloud services - defining features......................................................................................................... 8

3. Cloud services in standard product classifications................................................................................. 10

United Nations Central Product Classification (CPC) ................................................................... 10

European Statistical classification of products by activity (CPA) ................................................... 13

North American Product Classification System (NAPCS) ......................................................... 14

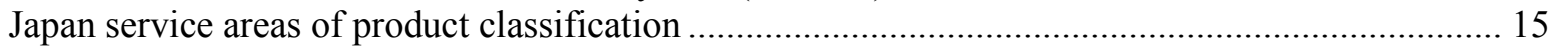

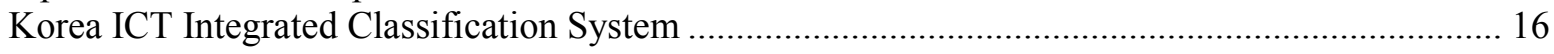

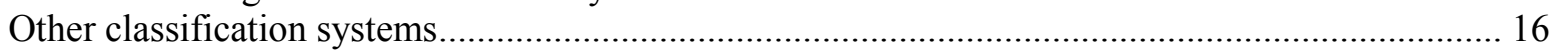

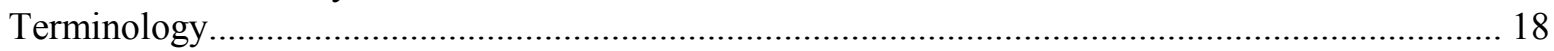

4. Data on business use of cloud-containing product categories ......................................................... 21

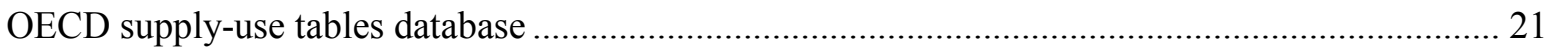

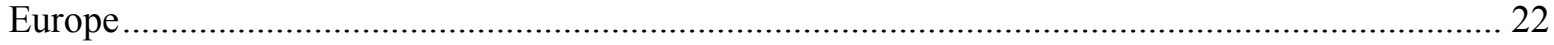

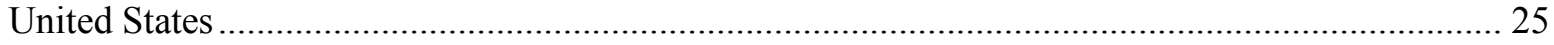

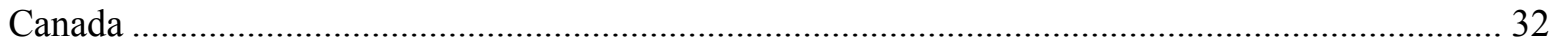

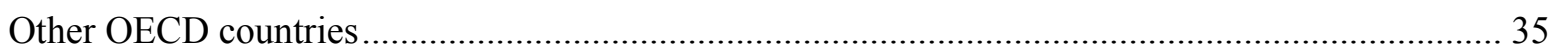

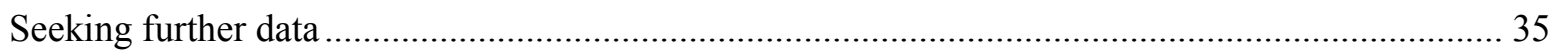

5. Estimating the use of specific cloud-containing product categories in other countries ............. 41

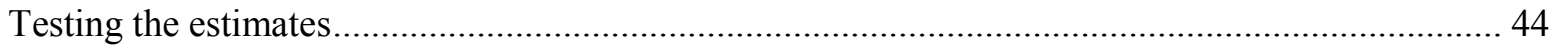

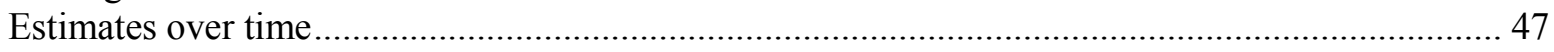

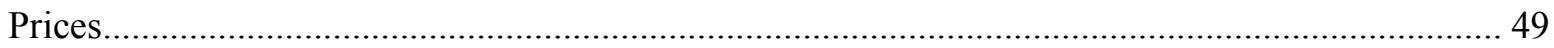

6. Conclusions and further work................................................................................................................... 53

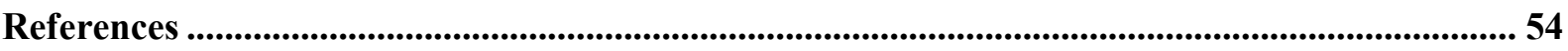

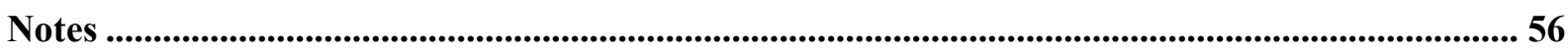




\section{FIGURES}

Figure 1. Vendor and consumer roles in Cloud Service models ...................................................... 11

Figure 2. Hierarchy of cloud-containing information services product categories ............................... 19

Figure 3. Intermediate use of broad cloud-containing product categories, latest available year ......... 22

Figure 4. Turnover from narrow cloud-containing product categories, 2015-17............................... 24

Figure 5. Use of "Data processing, Internet publishing, and other information services" by businesses (broad), 2012-17

Figure 6. Use of "data processing, Internet publishing, and other information services" component

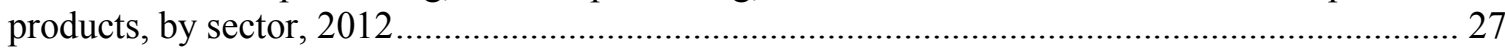

Figure 7. Estimated expenses for employer firms, annual average growth, 2012-2017...................... 28

Figure 8. Estimated "data processing, hosting and related services" (narrow) within use of "data processing, Internet publishing, and other Information services (broad), 2017 ........................... 29

Figure 9. Estimated share of specific cloud-containing product categories in "data processing, Internet publishing, and other information services" use, United States, 2012-2018 .................. 32

Figure 10. Intermediate use of "Data processing, hosting and related services", Canada, 2012-2016, 33

Figure 11. Use: additional breakdowns within intermediate consumption of "Computer programming, consultancy, and related services; Information services" .................................... 37

Figure 12. Use: Total intermediate consumption of specific cloud-containing product classes,

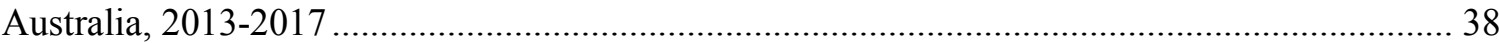

Figure 13. Enterprise expenditure on cloud services, Russian Federation........................................... 39

Figure 14. Data processing, hosting, and related services, 2012-2018 ............................................... 39

Figure 15. Sub-components of "Data processing, hosting, and related services" turnover, Spain, 2016-2018

Figure 16. Estimated intermediate use of specific cloud-containing products, latest available year .... 44

Figure 17. Estimated business use of specific cloud-containing products (USD millions) and the estimated number of active employer enterprises paying for cloud services (thousands)............. 46

Figure 18. Estimated average expenditure on cloud services per active employer enterprise, latest

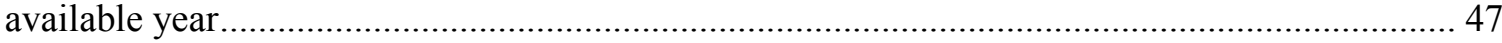

Figure 19. Nominal annual average growth rate of business use of specific cloud containing

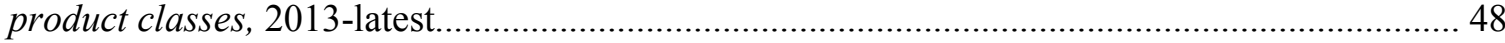

Figure 20. Information Service Activities, total output price index, European countries .................... 50

Figure 21. Data processing, hosting and related activities; web portals, total output price index, European countries

Figure 22. Producer price index: hosting, application service provisioning and other IT infrastructure provisioning services, United States

Figure 23. Price index (nominal and quality-adjusted) for AWS General Purpose EC2 xlarge Linux instance, 2010Q1-2019Q3

\section{TABLES}

Table 1. Cloud Service Industry in Korea ICT Integrated Classification System

Table 2. Product categories containing online software/online games in CPC, CPA, NAPCS

Table 3. Share of turnover from CPA J63.11 "Data processing, hosting, and related services" products (narrow) in turnover from J63 "Information Services" (broad) and J62-63 "Computer programming, consultancy and related services; Information services" (broad), by industry, 2015-17.

Table 4. Sales receipts from specific cloud-containing product categories, United States, 2012......... 30

Table 5. Sales receipts from specific cloud-containing product categories, and shares of parent

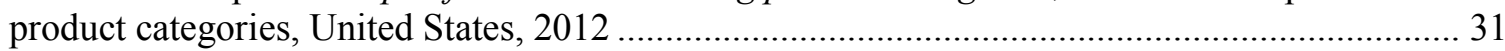

Table 6. Sales receipts for narrow cloud-containing product categories, Canada, 2013-2018 ............. 34 
Table 7. Use of "Information Services" products as a share of "Computer programming, consultancy, and related services; Information services".

Table 8. Derived adjustment factors to estimate intermediate use specific cloud-containing products from "Computer programming, consultancy, and related services; Information Services".......... 42

Table 9. Correlation between estimated intermediate use of specific cloud-containing products and businesses reporting paying for cloud services on ICT usage surveys...... 


\title{
Measuring Cloud Services use by businesses
}

\author{
Summary
}

Cloud infrastructures underpin an ever-increasing range of online services and tools used by businesses, other organisations, and individuals. They play an important role in enabling many firms to do business. However, measures based on surveys of ICT usage in business, give only a partial view of the diffusion of cloud services; they do not reveal the intensity or volume of use by businesses, or the amount businesses spend on cloud services. Nor do they inform about the supply of these services. This paper assesses the extent to which insights on the use of commercial cloud services (i.e. services purchased from external providers) can be gleaned from economic and business statistics - in particular from Supply-Use tables and the underlying business surveys.

The paper starts by examining the defining features of cloud services products and assessing how such products are likely to be classified in various international standard product classification systems. An important finding is that most of these systems do not allow for cloud services to be fully delineated because, even within the most detailed level of product breakdowns available, those products may or may not be based on a cloud architecture. The term "cloud containing product categories" is therefore introduced.

The level of detail available in published data sources is a further significant challenge. Use tables, a natural starting point when considering business expenditures on specific products, typically present only broad cloud-containing product categories. It is therefore necessary to seek sources offering more detailed disaggregation. The most detailed data discovered are 2012 US Economic Census (revenue by) product line data, supply-side series which can be used to estimate the share of specific cloud-containing product categories in parent product category revenue. It should be noted, however, that cloud services output and use are likely to have grown since 2012. It is not known whether growth in the broader aggregates available for more recent years suitably approximate those for the specific cloud-containing (sub)categories. The 2017 US Economic Census data, due to be published in 2021, will provide further insight into this.

It is possible to apply these shares derived on the supply-side to the use-side. However, this approach requires strong assumptions. Likewise, the approach can be applied across countries, with even stronger assumptions. A key challenge is the availability of detailed data for different countries, which would avoid or reduce the need assume that information from countries with data can be applied to others without data available. This lack of data significantly impedes the development of meaningful indicators and insights into the role of cloud services in businesses. Furthermore, these limitations perturb and distort the ability to understand digital transformation. Only an international effort focused on modernising statistical classifications and implementing them in data collections can improve the situation. 


\section{Introduction}

Cloud infrastructures underpin an ever-increasing range of online services and tools used by businesses (and individuals). In OECD countries, over one third of businesses purchased some form of cloud services in 2018 (OECD, 2019 ${ }_{[1]}$ ), up from 20\% in 2015 (OECD, 2017[2]).

However, such measures, which are based on surveys of ICT usage in business, give only a partial view of the diffusion of cloud services; they do not reveal the intensity or volume of use by businesses, or the amount businesses spend on cloud services. Nor do they inform about the supply of these services.

This paper looks at the availability of information on cloud services in supply-use tables and underlying business statistics sources. It starts by looking at the defining features of cloud services as products, then considers their treatment in various standard product classification systems used in OECD countries. Following this, the availability of data for the relevant product categories is examined before a range of estimates of national business expenditure on purchases of cloud services is derived. 


\section{Cloud services - defining features}

OECD $\left(2014_{[3]}\right)$ provided a high-level definition of cloud computing as follows:

"Computing services based on a set of computing resources that can be accessed in a flexible, elastic, on-demand way with low management effort."

However, further details are needed in order to identify cloud services in a statistical context. The US National Institute of Standards and Technology (Mell and Grance, 2011 $1_{[4]}$ ) identifies five "essential characteristics" of cloud computing:

a. On-demand self-service. A consumer can unilaterally provision computing capabilities, such as server time and network storage, as needed automatically without requiring human interaction with each service provider.

b. Broad network access. Capabilities are available over the network and accessed through standard mechanisms that promote use by heterogeneous thin or thick client platforms (e.g., mobile phones, tablets, laptops, and workstations).

c. Resource pooling. The provider's computing resources are pooled to serve multiple consumers using a multi-tenant model, with different physical and virtual resources dynamically assigned and reassigned according to consumer demand. There is a sense of location independence in that the customer generally has no control or knowledge over the exact location of the provided resources but may be able to specify location at a higher level of abstraction (e.g., country, state, or datacenter). Examples of resources include storage, processing, memory, and network bandwidth.

d. Rapid elasticity. Capabilities can be elastically provisioned and released, in some cases automatically, to scale rapidly outward and inward commensurate with demand. To the consumer, the capabilities available for provisioning often appear to be unlimited and can be appropriated in any quantity at any time.

e. Measured service. Cloud systems automatically control and optimize resource use by leveraging a metering capability at some level of abstraction appropriate to the type of service (e.g., storage, processing, bandwidth, and active user accounts). Resource usage can be monitored, controlled, and reported, providing transparency for both the provider and consumer of the utilized service ${ }^{1}$.

These essential features may be useful when trying to identify where cloud services sit within standard product classifications. Within cloud computing, a number of "service models" are also routinely identified:

- Infrastructure as a Service (IaaS). The capability provided to the consumer is to provision processing, storage, networks, and other fundamental computing resources where the consumer is able to deploy and run arbitrary software, which can include operating systems and applications. The consumer does not manage or control the underlying cloud infrastructure but has control over operating systems, storage, and deployed applications; and possibly limited control of select networking components (e.g., host firewalls).

- Platform as a Service (PaaS). The capability provided to the consumer is to deploy onto the cloud infrastructure consumer-created or acquired applications created 
using programming languages, libraries, services, and tools supported by the provider (or from other, compatible sources). The consumer does not manage or control the underlying cloud infrastructure including network, servers, operating systems, or storage, but has control over the deployed applications and possibly configuration settings for the application-hosting environment.

- Software as a Service (SaaS). The capability provided to the consumer is to use the provider's applications running on a cloud infrastructure. The applications are accessible from various client devices through either a thin client interface, such as a web browser (e.g., web-based email), or a program interface. The consumer does not manage or control the underlying cloud infrastructure including network, servers, operating systems, storage, or even individual application capabilities, with the possible exception of limited user-specific application configuration settings.

In some classification systems yet further types may be identified. This illustrates that "cloud services" are not monolithic but rather a class of products in which the cloud service vendor manages and controls the product. At a minimum, this control is of the underlying cloud infrastructure of processing, storage, networks, and other fundamental computing resources (IaaS). However, the provider may also manage and control the operating systems running on the cloud infrastructure (PaaS), and/or the applications running within those operating systems (SaaS). By definition, the more the provider manages and controls, the less the customer is able to manage and control. This reduced flexibility entails reduced responsibility and needs for technical expertise - key benefits of adopting cloud services.

Common across all three service models is provision, by the vendor, of fundamental computing resources (hardware and software) for access by the customer. Furthermore, in order to be a cloud service, the resources provided must behave in a way that enables the five essential characteristics of cloud computing set out in paragraph 5. That is to say, rather than providing "one server for one consumer", the computing resources should be pooled to serve multiple consumers who access those resources (simultaneously) through networks (e.g. the Internet), which - coupled with on-demand self-service - enables rapid elasticity.

With these defining features in hand, and bearing in mind that cloud services are products first and foremost, a next step is to see how such products can be delineated in the major product classifications. 


\section{Cloud services in standard product classifications}

This section examines standard product classifications to identify the product categories most likely to cover cloud services.

\section{United Nations Central Product Classification (CPC)}

CPC v2.1 (United Nations, Statistics Division, 2015 $5_{[5]}$ ) includes a number of potentially relevant product classes within "8315 Hosting and information technology (IT) provisioning services". Most notably, "83152 Application Service Provisioning" bears quite some similarity to cloud services. In particular, it specifies that services are provided using a "centralised, hosted, and managed computing environment" which well describes the fundamental computing resources underlying cloud services. However, the text also specifies that only software applications are concerned and thus appears to imply that this subclass covers SaaS only - since in PaaS and IaaS the vendor's service does not include the provision or management of applications (see Figure 1).

\section{Application service provisioning}

This subclass includes:

- provision of leased software applications from a centralised, hosted, and managed computing environment:

-- with integration to the systems and infrastructure of the client. (Frequently, consulting, customization, and systems integration services are bundled with the hosting or management of the application).

-- where the leased application is not customised and not integrated with other applications of the client. (The application is usually accessed over the World Wide Web. A common example is office suite software applications).

On the face of it, this category appears likely to include a good portion of cloud service provision. However, a computing environment can be "centralised, hosted, and managed" without using cloud computing that enables the five essential characteristics noted above. As such, this class is likely to contain some degree of non-cloud services - though it might be expected that the share of these would be falling over time as cloud approaches become increasingly ubiquitous. 
Figure 1. Vendor and consumer roles in Cloud Service models

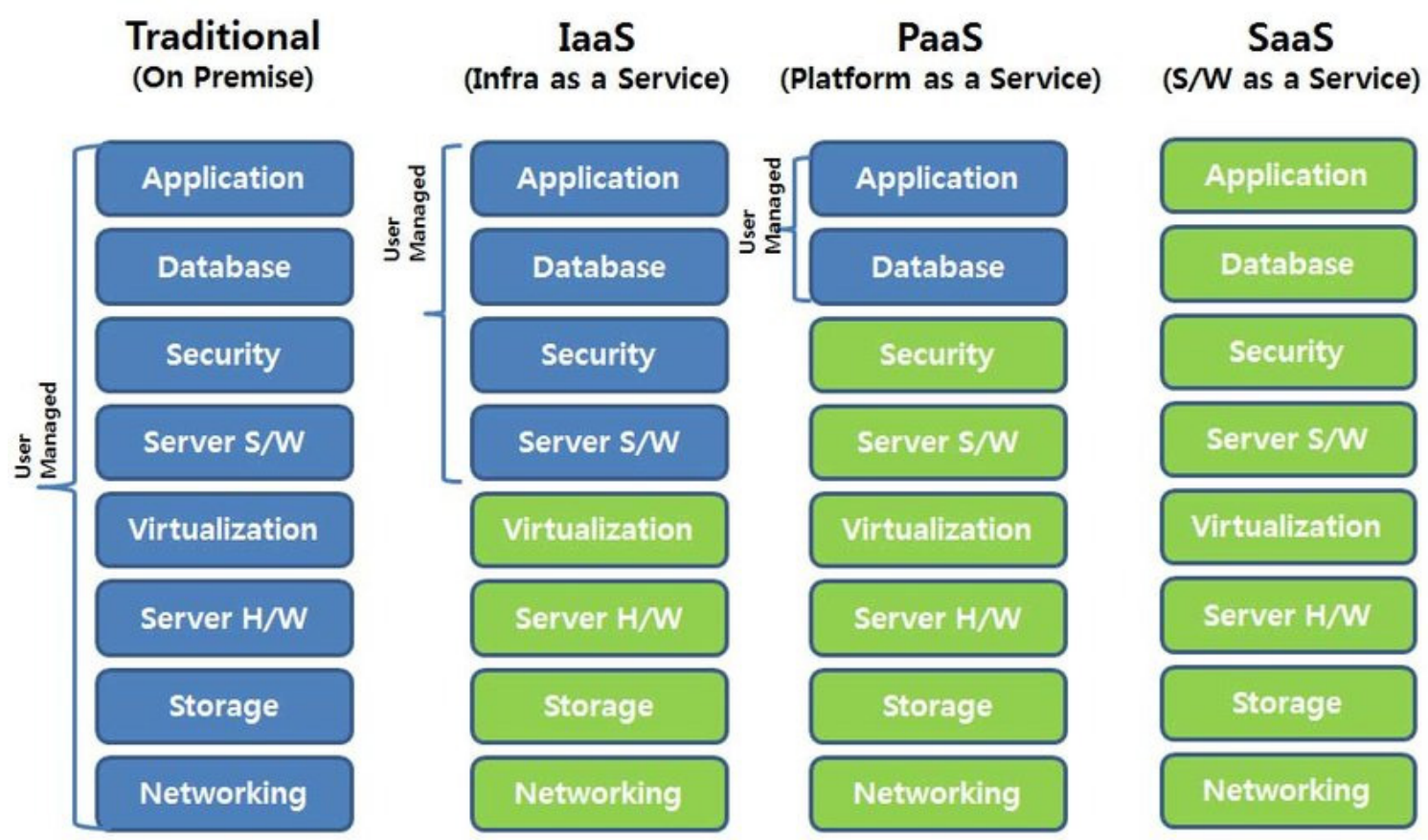

Source: (Jung, Cho and Tak, 2017[6]) reproduced in accordance with Creative Commons Attribution 4.0 International Public License (https://creativecommons.org/licenses/by/4.0/).

Furthermore, the text specifies that these software applications are leased ${ }^{2}$. It is not completely clear if that term refers to the software being leased to the cloud services provider to offer to their customers, or if it is describing the provision of the software by the cloud service provider to the end customer as being more like a lease than a sale. If the former is the case, it is not completely clear what the implications are for the recording of services where the software code is not leased to but owned by the cloud service provider. Further effort is needed to clarify the interpretation of this and its implications. It should be borne in mind that major SaaS players such as Oracle, Salesforce, and SAP (Dignan, $\left.2019 \mathrm{a}_{[7]}\right)$ offer proprietary software applications as their core service, while the main providers of cloud infrastructure (IaaS) - AWS, Microsoft Azure, Alibaba, and Google (Gartner, 2019 $9_{[8]}$ ) all also offer proprietary applications as a key component of their business (from online email applications to advanced data analytics applications). It is important to understand how these SaaS services are treated in theory and are being recorded in practice (i.e. in class 83152 or elsewhere).

It is then necessary to consider where PaaS and IaaS are classified, if not in 83152. Likewise, where service provisioning of non-licensed software applications would be recorded.

Amongst other classes within 8315 Hosting and information technology (IT) infrastructure provisioning services, items within "83159 Other hosting and IT infrastructure provisioning services" appear to come close to describing certain elements of cloud services. To examine each in turn:

- "colocation service" providers provide a building ("colocation centre") in which multiple customers install their physical ICT infrastructure, usually servers. The 
servers belong to and are operated by the entity that put them there, not the building owner or operator. As such, the description of "collocation services" specifies that "clients are responsible for management of the operating system, hardware, and software". This is different from a cloud service model, in which it is the vendor that is responsible for hardware (and in the case of PaaS or IaaS elements of software too) and so these are not cloud services.

- "data management services" appears to relate to various bespoke services performed by a vendor rather than to SaaS applications allowing the customer to perform data modelling, etc. and hence does not appear to be a cloud service.

- "video and audio streaming services" are products which, from some viewpoints, may appear to be an example of SaaS. However, it can be argued that the main product of streaming sites is access to content, with the software used to access, search, and play that content being secondary ${ }^{3}$.

- "data storage services" appears to describe one important element of IaaS, although whether or not a specific product should be counted among cloud services will depend on the use of an underlying cloud infrastructure.

- "other IT hosting or infrastructure provisioning services" appears likely to cover PaaS ("hosting clients application[s]") and may also cover another aspect of IaaS ("processing client's data and computer time-share").

\section{Other hosting and IT infrastructure provisioning services}

This subclass includes:

- co-location services, i.e. the provision of rack space within a secured facility for the placement of servers and enterprise platforms. (The service includes the space for the client's hardware and software, connection to the Internet or other communication networks, and routine monitoring of servers. Clients are responsible for the management of the operating system, hardware, and software).

- data storage services, i.e. managing or administering the storage and back-up management of data such as remote back-up services, storage, or hierarchical storage management (migration).

- data management services, i.e. on-going management and administration of data as an organisational resource. (Services may include performing data modelling, data mobilisation, data mapping/rationalisation, data mining and system architecture.

- video and audio streaming services, i.e. sending audio and video data over the Internet or providing services associated with the storage, production (including encoding), and support of video and audio streaming over the Internet.

- other IT hosting or infrastructure provisioning services such as hosting a client's application, processing clients' data and computer time-share.

Class 8315 also includes " 83151 Website hosting services", which involves "provision of the infrastructure to host a customer's website and related files in a location that provides fast, reliable connection to the Internet. A note to this category notes that "an important characteristic of this service is [...] Internet connections that can be quickly scaled to accommodate variations in traffic use". While this sounds similar to the scalability of cloud services, it relates to scalability of not just networks but storage, processor cycles, etc. Web 
hosting services would only be cloud services if they rely on an underlying cloud infrastructure, and may be PaaS or SaaS depending on the precise services provided.

\section{Website hosting services}

This subclass includes:

- provision of the infrastructure to host a customer's website and related files in a location that provides fast, reliable, connection to the Internet that may be:

-- limited to storage on a single server, in either shared or dedicated capacity, without the service provider managing or integrating software applications. (Software hosted on the server is the client's responsibility and service level guarantees are standardised and limited in scope).

-- a bundled service package that consists of the hosting and management of the website and related applications.

Note: An important characteristic of this service is the promise of a secure and reliable site and Internet connections that can be quickly scaled to accommodate variations in traffic use. Frequently, consulting, customisation and systems integration are part of the package. Applications are frequently e-commercerelated and enable on-line storefronts, shopping carts and catalogues with advanced and complex features such as order processing, fulfilment, procurement, invoicing, transaction processing, customer relations management and back-end database and data warehouse integration and migration services.

Several other potentially relevant categories exist in the CPC. "84392 On-line software", which comprises "software that is intended to be executed on-line, except game software" is likely to capture elements of SaaS. In particular, it could house "application service provisioning" of non-leased applications (i.e. software that the cloud services vendor owns rather than licenses), though it is likely that recording practice will vary between countries. Similarly, "84391 On-line games", which comprises "games intended to be played on the Internet" is likely to include some SaaS. However, it may also include online games that are actually executed on users' own hardware rather than on-line. Furthermore, the specific products in these subclasses should only be counted among cloud services if the underlying infrastructure they are running on has a cloud architecture enabling the five essential characteristics of cloud services.

Australia and New Zealand are examples of OECD countries which adopt the CPC directly (ABS, 2001 ${ }_{[9]}$ ).

\section{European Statistical classification of products by activity (CPA)}

The CPA is used within the European Statistical System (Eurostat, 2015 $5_{[10]}$ ). It is identical to the CPC with respect to the categories identified above. However, the CPA sets out additional layers of aggregation of these products. In particular, "Web hosting services" (63.11.12), "Application service provisioning" (63.11.13) and "Other hosting and IT infrastructure provisioning services" (63.11.19) are combined with "data processing services" (63.11.11) and also "Advertising space or time in Internet" (63.11.2 - which excludes advertising in Internet books, newspapers, journals and periodicals, or on web portals). 
Tag and Pitkanen $\left(2018_{[11]}\right)$, suggest that both PaaS and IaaS might belong to class 63.11 "Data processing, hosting, and related services", though they do not go as far as identifying the relevant sub-classes. While SaaS might be classified to either 58.29.40 "online software" (within software publishing) or 63.11.13 "application service provisioning":

"In particular, it might be problematic to determine a suitable subcategory for SaaS: it could be classified to either 58.29.40 Online-Software or 63.11.13 Application service provisioning in the CPA classification. Usually, provision of a leased software belongs to class 63.11. If the service provider has copyrights for a software, the activity could be classified to publishing activities e.g. 58.29, Software publishing." (Tag and Pitkanen, 2018 $\left.{ }_{[11]}\right)$

Tag and Pitkanen also draw attention to the earlier work of the "Eurostat Task-Force on Price and Volume Measures for Service Activities" (Eurostat, 2018 [12]), which, while agreeing that IaaS is likely to be classified within CPA 63.11.1 "Data processing, hosting, application services and other IT infrastructure provisioning services, states that "The supply of SaaS should be classified with other software: CPA 58.2 (Software publishing services)" - seemingly concluding that all SaaS should be classified as "online software" (CPA 58.29.4) rather than in "application service provisioning" (CPA 63.11.13). Furthermore, it concludes that "PaaS is most likely CPA 62.01 (Computer Programming Services)", however the rationale is not given and is not clear from the definitions of subclasses, which relate to services in which the provider's main task is coding software (rather than providing cloud infrastructure).

On the face of it, CPA class 63.11.11 "Data processing services" sounds like it could include some cloud services. However, the description text states that "This subcategory includes: complete processing services and specialised reports from data supplied by clients or providing automatised data processing and data entry services, including database running services". While there may be some specific cloud services that meet this description, this appears to aim to describe a product that is not "self-service" (one of the defining features of cloud services) but in which a client firm provides its data which the service provider's personnel analyse and report on, as well as services where the service provider undertakes data entry on behalf of the client firm (again, this does not sound "selfservice"). For this reason, and due to being specific to the CPA, this product class is not included in the analyses presented.

\section{North American Product Classification System (NAPCS)}

The NAPCS is intended to be used in Canada, Mexico, and the United States (INEGI, n.d. ${ }_{[13]}$ ), though only the Canadian and US have published national implementations at this time. There are some variations between the level of detail set out in the Canadian and US implementations, with the former setting out detailed definitions and additional breakdowns (Statistics Canada, 2018 ${ }_{[14]}$ ), in comparison to the latter, which sets out only product category titles with no definitions (US Census Bureau, n.d.[15]).

NAPCS is not based directly on the CPC but has many similarities and has been linked through conversion tables. A notable difference is that the items bundled within CPC 83159 "Other hosting and IT infrastructure provisioning services" are separated into individual categories in NAPCS. This is of significant benefit when trying to identify cloud services as closely as possible because irrelevant categories can be excluded. However, the NAPCS still suffers from the same limitation as the $\mathrm{CPC}$ and $\mathrm{CPA}$ - that products within even these detailed classes should only be counted as cloud services if the underlying infrastructure 
uses a cloud architecture. It should be noted, though, that the Canadian version of NAPCS seeks to delineate application service provisioning in to cloud-based and non-cloud varieties, providing a single, discrete category for SaaS (NAPCS does not have the separate category for "online software" included in the CPC and CPA).

In addition, the Canadian NAPCS separates out "on-line gaming services", some of which could be SaaS. In addition, although the NAPCS structure file available from the US Census Bureau does not contain such a category, the "2012 product code to 2017 NAPCSbased collection code" concordance table (US Census Bureau, 2019 $9_{[16]}$ ) includes a similar category for "Internet gaming".

The NAPCS 2017 structure is as follows:

- Web site hosting services

- Application service provisioning

- Except SaaS, on cloud (CAN only)

- SaaS on cloud (CAN only)

- Collocation services (USA)/Information Technology (IT) infrastructure colocation services (except telecommunications facilities) (CAN)

- Data storage services (USA)/Data storage infrastructure provisioning services (CAN)

- Data management services (USA)/Data management infrastructure provisioning services (CAN)

- Video and audio streaming services (USA)/Video and audio streaming infrastructure provisioning services $(\mathrm{CAN})$

- Other data processing or IT infrastructure provisioning services.

- On-line gaming services (except gambling) (CAN) / Internet gaming (USA)

\section{Japan service areas of product classification}

The "Service areas of product classification 2019" (MIC, 2019[17]) makes specific reference to cloud services in the definition of several categories:

- A specific category is provided for IaaS and PaaS: sub-product 37002406 "ICT infrastructure shared services". This is defined as "Services that provide fundamental functions for systems/applications to be built upon, including services provided through networks whereby users share equipment or facilities (e.g. servers or storages in data centres). IaaS, PaaS."

- SaaS is recorded within 40102100 "ICT applications shared services" and broken down into the following categories. The services are described as "using networks, servers in data centres, equipment, and storage facilities shared with other users to provide application services":

○ 40102103 "ICT applications shared services for business"

○ 40102106 "ICT application shared services for households (excluding games)"

○ 40102109 "Game application sharing service" 


\section{Korea ICT Integrated Classification System}

In Korea, a specific "Cloud Industry Survey" is conducted annually by NIPA (the National ICT Promotion Agency) and the Ministry of Science and ICT. It aims to monitor the status of the cloud industry in Korea and provide policymakers with data used to facilitate the industry.

As well as the Korean Standard Industrial Classification (KSIC 10, which is industry rather than product-based), a specific "ICT Integrated Classification System" is also used to target the survey. Many of the classes listed are similar to those in the the other classification systems reviewed (Table 1). However, as is the case in most other classification systems, products based on cloud infrastructure are not delineated from others.

Table 1. Cloud Service Industry in Korea ICT Integrated Classification System

\begin{tabular}{|c|c|}
\hline No. & Class title \\
\hline 2314.0000 & Internet management service \\
\hline 2312.1000 & Hosting and co-location service \\
\hline 2312.2000 & Content delivery support system \\
\hline 2314.1000 & Online storage sharing service \\
\hline 3119.0000 & Others \\
\hline 3114.0000 & IT operation management \\
\hline 3115.0000 & Data analysis and management \\
\hline 3113.0000 & Storage \\
\hline 3111.0000 & Operating System \\
\hline 3129.0000 & Others \\
\hline 1213.9000 & Other computer parts \\
\hline 1219.0000 & Other computer \\
\hline 1311.5400 & Network security equipment \\
\hline 2319.0000 & Other Information infrastructure service \\
\hline 2311.0000 & Data processing service \\
\hline 2312.0000 & Hosting service \\
\hline 3117.0000 & Application development and testing \\
\hline 3110.0000 & System software \\
\hline 2312.1200 & Application hosting \\
\hline 3122.9000 & SW Other general purpose industrial software \\
\hline 3300.0000 & IT service \\
\hline 3112.0000 & Security \\
\hline 3311.0000 & IT Consulting \\
\hline
\end{tabular}

Source: NIPA and MSIT, Korea.

\section{Other classification systems}

Other countries may use alternative classification systems. However, none were flagged by WPMADE delegates as containing particular information relevant to cloud services. 
In any case, the CPC, CPA, and NAPCS provide a reasonable basis for examining and comparing the data available in a majority of OECD countries.

\section{Summary}

The CPC, CPA, and NAPCS are rather similar in the items covered by these categories. However, NAPCS provides more detail by providing separate sub-categories for items that the CPC and CPA bundle together with other items that do not appear likely to be cloud services. By contrast, the CPC and CPA provide separate categories for online software, which is classified elsewhere in the NAPCS.

The product categories which appear to be most likely to contain cloud services are:

1. Web site hosting services (CPC, CPA, NAPCS)

2. Application service provisioning (CPC, CPA, NAPCS)

3. Data storage services (NAPCS; CPC and CPC bundle these within "other hosting and IT infrastructure provisioning")

4. Other data processing or IT infrastructure provisioning services (NAPCS; CPC and CPC bundle these within "other hosting and IT infrastructure provisioning")

5. Online software (CPC, CPA)

6. Online games (CPC, CPA, NAPCS)

In all these cases, services built on cloud infrastructure would ideally be distinguished as only those are cloud services. However, such detail is not generally available in practice. As such, these products are best interpreted as those which are most likely to house cloud services or, perhaps, most likely to be mainly cloud services.

The other products discussed would ideally be excluded from analysis for the following reasons. However, in practice this may not be possible where countries implement the $\mathrm{CPC} / \mathrm{CPA}$.

- Data management services appears to relate to various bespoke services performed by a vendor rather than to SaaS applications allowing the customer to perform data modelling, etc. and hence does not appear to be a cloud service.

- Video and Audio streaming services bear close similarity to PaaS but the main product is a library of content rather than the software used to search and play it.

In addition, the sub-classes within Computer programming services do not clearly relate to cloud services as they focus on the activity of coding software rather than the provision of cloud services. There may, nevertheless, be some relevant custom coding for cloud services within these products that would ideally be isolated for inclusion in any measure of cloud services but that is unlikely to be possible with the detail provided in publicly available data.

The Japanese classification of services products differs quite markedly from the CPC. In so doing, it specifies specific sub categories for IaaS, PaaS, and SaaS. It should therefore be simple to use the breakdown to produce an aggregate for cloud services. 


\section{Terminology}

With the exception of the products within the Japan product classification and one specific sub-product within the Canadian implementation of the NAPCS, none of the product categories identified contain exclusively cloud services. For this reason, the term "cloudcontaining product categories" will be adopted. Furthermore, in the available data sources, these specific cloud-containing product categories are often aggregated with other product categories that are not, or do not appear likely to include, cloud services. To make it easier to articulate the extent to which such extraneous products are included in the aggregates available, the following terminology will be used:

- Specific cloud-containing product categories - the categories most tightly capturing cloud services products

- Narrow cloud-containing product categories - mid-level aggregates/categories grouping the specific categories with a relatively small number of extraneous categories.

- Broad cloud-containing categories - higher level aggregates grouping the relevant specific categories with a considerable number of other product categories.

This approach is further illustrated for the information services product categories of the $\mathrm{CPA} / \mathrm{CPC}$ and NAPCS in Figure 2.

In the Japan service areas of product classification, which is not shown in the figure, "ICT infrastructure shared services" is a specific IaaS and PaaS cloud services category, while the parent narrow cloud-containing product category is "ICT equipment and facilities shared services".

With respect to online games/software; the different classification schema adopt differing product hierarchies, as set out in Table 2.

The next section looks at the availability of data for these cloud-containing product categories. 
Figure 2. Hierarchy of cloud-containing information services product categories

CPC, CPA, NAPCS, and related data collections.

Computer programming, consultancy, and related services; Information services (Eurostat, OECD supply-use databases)

Information services (CPA 63.) /

Data processing, Internet publishing, and other Information services (US annual supply-use tables)*

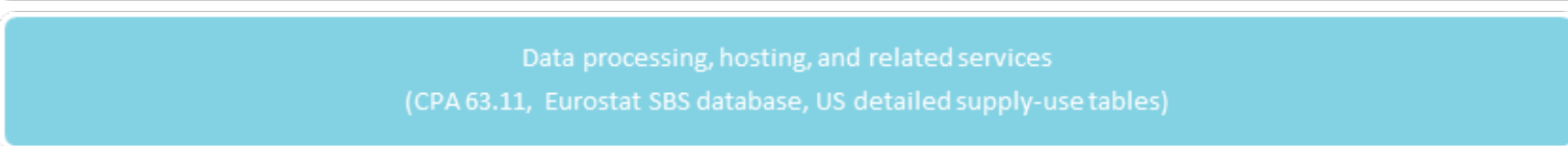

\begin{tabular}{|c|c|c|c|}
\hline $\begin{array}{l}\text { Data } \\
\text { processing } \\
\text { services } \\
\text { 63.11.11] }\end{array}$ & $\begin{array}{l}\text { Hosting and IT infrastructure provisioning services } \\
\text { (CPC } 8315 \text { / CAN services data) }\end{array}$ & $\begin{array}{l}\text { Advertising } \\
\text { space or time. } \\
\text { on Intemet** } \\
\text { (CPA 63.11.2) }\end{array}$ & $\begin{array}{l}\text { Information and } \\
\text { document } \\
\text { transformation } \\
\text { [MAPCS) }\end{array}$ \\
\hline
\end{tabular}

\begin{tabular}{|c|c|c|c|c|c|c|c|}
\hline \multirow[t]{2}{*}{ 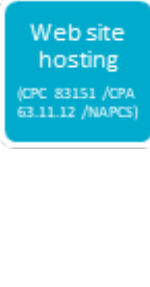 } & \multicolumn{2}{|c|}{$\begin{array}{l}\text { Application service } \\
\text { provisioning } \\
\text { (CPC 83152/CPA 63.11.13 } \\
\text { /NAPCS) }\end{array}$} & \multicolumn{5}{|c|}{$\begin{array}{l}\text { Other hosting and IT provisioning services } \\
\qquad \text { (CPC 83159/CPA 63.11.19) }\end{array}$} \\
\hline & $\begin{array}{l}\text { Except Saas, } \\
\text { on coud (CAN } \\
\text { only) }\end{array}$ & $\begin{array}{l}\text { Saas on cloud } \\
\text { [CAN only] }\end{array}$ & $\begin{array}{l}\text { colocation } \\
\text { services } \\
\text { (NAPCS) }\end{array}$ & $\begin{array}{l}\text { Data storage } \\
\text { services } \\
\text { (NAPCS) }\end{array}$ & $\begin{array}{l}\text { Data } \\
\text { management } \\
\text { services } \\
\text { (NAPCS) }\end{array}$ & $\begin{array}{l}\text { Video and } \\
\text { audo } \\
\text { streaming } \\
\text { services } \\
\text { (NAPCS) }\end{array}$ & 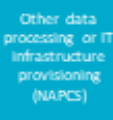 \\
\hline
\end{tabular}

Legend:

Broad cloud-contain 
Note to Figure 2: The precise naming of product classes can vary somewhat between CPC, CPA, and NAPCS *"Data processing, Internet publishing, and other information services", as presented in the US annual supplyuse tables also includes "Internet publishing and broadcasting". This category was used in the 2012 system of product and service codes but, under NAPCS 2017, its contents would be disbursed across a considerable number of categories including newspapers and periodicals, various categories of books, dating services, directories, speciality content, and databases and other collections of information.

** In the CPA, "other information services" includes: information search services on a fee or contract basis; news clipping services, press clipping services etc.; compilation services of facts and information other than mailing lists; automatised computer-based information services n.e.c. The equivalent category in the 2012 US detailed supply-use tables is broader, including "News syndicates, libraries, archives and all other information services".

*** In the CPA "Data processing, hosting, and related services" includes "Advertising space or time in Internet". However, this class explicitly excludes advertising space in Internet books newspapers, journals and periodicals (included in Publishing services) and "Internet advertising space in web portals" (included in Web Portal Services).

Source for Figure 2: OECD based on CPC 2.1, CPA 2.1, NAPCS, and related data collections.]

Table 2. Product categories containing online software/online games in CPC, CPA, NAPCS

\begin{tabular}{|c|c|c|c|c|}
\hline & $\begin{array}{c}\text { Specific cloud- } \\
\text { containing categories }\end{array}$ & $\begin{array}{l}\text { Narrow cloud- } \\
\text { containing categories }\end{array}$ & $\begin{array}{l}\text { Broad cloud- } \\
\text { containing categories }\end{array}$ & Notes \\
\hline CPC & $\begin{array}{l}\text { On-line software } \\
\text { On-line games }\end{array}$ & Other online content & On-line content & \\
\hline CPA & $\begin{array}{l}\text { On-line software } \\
\text { On-line games }\end{array}$ & $\begin{array}{r}\text { Software publishing } \\
\text { services }\end{array}$ & Publishing services & \\
\hline $\begin{array}{l}\text { Japan service areas } \\
\text { of product } \\
\text { classification }\end{array}$ & $\begin{array}{r}\text { ICT applications } \\
\text { shared services } \\
\text { - for business } \\
\text { - for households } \\
\text { (excluding games) } \\
\text { - Game application } \\
\text { sharing service }\end{array}$ & & & $\begin{array}{l}\text { These products are cloud } \\
\text { services only. According to the } \\
\text { classification structure there is no } \\
\text { parent cloud-containing product } \\
\text { category. }\end{array}$ \\
\hline CanNAPCS & $\begin{array}{r}\text { Online gaming } \\
\text { services }\end{array}$ & $\begin{array}{r}\text { Broadcasting and } \\
\text { online games } \\
\text { distribution services }\end{array}$ & $\begin{array}{r}\text { Telecommunications, } \\
\text { broadcasting } \\
\text { distribution, and } \\
\text { related services }\end{array}$ & $\begin{array}{r}\text { Software and software licensing } \\
\text { specifically excludes hosted } \\
\text { software services" (i.e. SaaS), } \\
\text { which is classified in "application } \\
\text { service provisioning" }\end{array}$ \\
\hline \multirow[t]{2}{*}{ US NAPCS } & & $\begin{array}{r}\text { Published computer } \\
\text { software }\end{array}$ & $\begin{array}{l}\text { Computer software } \\
\text { and related products }\end{array}$ & $\begin{array}{l}\text { Unclear whether online software } \\
\text { classified in "application service } \\
\text { provisioning", as specified in the } \\
\text { CanNAPCS, or within software } \\
\text { publishing similar to CPC/CPA. }\end{array}$ \\
\hline & Internet gaming & $\begin{array}{r}\text { Speciality content for } \\
\text { consumers }\end{array}$ & $\begin{array}{r}\text { "Publishing industries, } \\
\text { except Internet } \\
\text { (includes software)" < } \\
\text { "Information" }\end{array}$ & $\begin{array}{l}\text { Not presented in NAPCS } \\
\text { structure file but included in the } \\
2012 \text { product code to NAPCS } \\
2017 \text { concordance table (both } \\
\text { from US Census bureau) }\end{array}$ \\
\hline
\end{tabular}

Source: OECD based on CPC 2.1, CPA 2.1, NAPCS, and related data collections. 


\section{Data on business use of cloud-containing product categories}

When considering the production and consumption of products, including cloud services products, supply-use tables are a natural starting point. However, these typically present relatively aggregated product groupings that do not provide the granular detail required to closely isolate categories containing cloud services. Detailed supply-use tables, which are produced less frequently (typically every five years or so, in relation to National Accounts benchmark revisions), as well as underlying structural business data available for some countries can provide some additional insights.

While "on-line games" have been identified as likely to be a cloud-containing product category, the focus here is on business' use of cloud services as inputs to their productive processes. While there are undoubtedly some businesses for which online-games are an intermediate input (e.g. e-sports leagues), it seems highly likely that the majority of on-line gaming services are likely to be used by households. For this reason, as well as a lack of data availability, on-line games will not be considered in this analysis.

\section{OECD supply-use tables database}

The OECD supply-use tables database collates data from OECD member and partner countries using standard industry and product classifications to facilitate cross-country comparisons. However, the product breakdowns available are relatively aggregated, with no detail available within "publishing services" and most countries providing only" a very broad computer programming, consultancy, and related services., Information Services" aggregate rather than the narrower (though still broad) "Information Services" category alone. A further issue is that, due to relatively long and variable lags in the time taken to publish Supply-Use tables, as well as sporadic availability, the latest available year can vary widely between countries - from 2012 in Turkey to 2019 in the Czech Republic.

Nevertheless, the available data, presented in Figure 3, provide several indications. Firstly, the consumption of broad cloud-containing product categories is far greater in the United States, at over USD 450 billion, than in other countries - the second-largest market, Germany, totals around USD 160 billion, while the United Kingdom follows with around USD 80 billion.

Secondly, publishing services is generally a relatively small portion of the overall total and it seems likely that "on-line software" will be only a small portion within that (bearing in mind that "Publishing Services" also covers print and digital publication of a wide range of other products such as books, directories and mailing lists, news, periodicals, games, and other software). For this reason, and given the general paucity of data at more detailed levels (e.g. "on-line software") and the differing aggregation of software publishing categories set out in Table 2, the main focus of the following analysis will be on cloud services recorded within the "Information Services" aggregate. 
Figure 3. Intermediate use of broad cloud-containing product categories, latest available year

USD billion, Purchasers' prices.

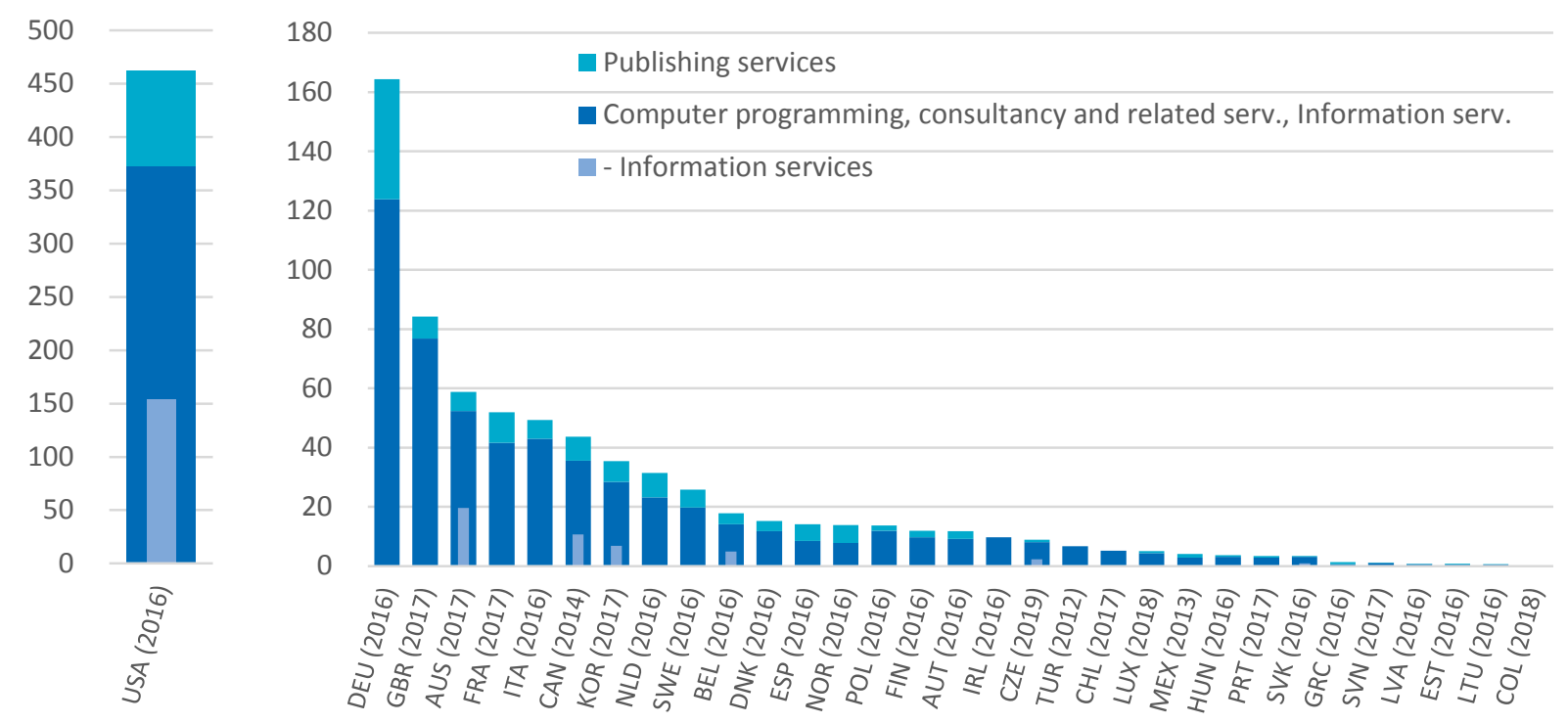

Note: Publishing services unavailable for Ireland.

Source: OECD Supply-Use Tables Database, July 2020.

Finally, the share of the broad "information services" category within the wider category that combines it with computer programming, consultancy, and related services, is relatively small in all countries, at one-third on average. This suggests that estimates of cloud services use will be more reliable the narrower are the categories available for use in estimation.

It is therefore necessary to seek data sources offering more detailed disaggregation. The following sections examine the data available from select sources.

\section{Europe}

Eurostat publishes supply-use tables for countries participating in the European Statistical System. However, as in the OECD database, the relevant categories are grouped along with many other products within broad cloud-containing product categories CPA J58 "Publishing Services" (online software, online games) and CPA J62-63 "Computer programming, consultancy and related services; Information services" (other relevant products).

It is therefore necessary to seek more detailed data. A logical next step is to look at the structural business survey data which underpin National Accounts and supply-use tables in most countries. With regard to purchases of services, Eurostat gathered some "Demand for services statistics" in 2003. As well as being old and only covering seven countries, they too provide only very aggregate product groups so are not suited to the task at hand.

Additional detail is available on the production side though. The Eurostat Business Services Statistics database provides services turnover with more specific product detail, although the relevant "potential cloud" products are still combined with various other 
products. "Web hosting services", "Application Service Provisioning", and "Other hosting and IT infrastructure provisioning services" are combined alongside "data processing services" and "advertising space or time in the Internet" within "Data processing, hosting, and related activities". Meanwhile, "on-line software" (potentially a cloud service product) is combined with "software downloads" (not cloud).Figure 4 presents the available data.

Together, these product categories were worth almost EUR 55 billion in 2017, with fourfifths of that being "data processing, hosting, and related activities". The key unknown is just how much of these parent categories is driven by the relevant specific cloud-containing sub-categories (which would themselves still contain various non-cloud service products).

However, the Eurostat Business Services Statistics database only covers firms classified in "business services" industries. Of these, the data suggest that the relevant product categories are only produced in three NACE/ISIC industry groups. The "computer programming, consultancy, and related activities" industry accounts for over half of turnover from these products. However, it should be noted that some of these absolute differences between industries may be influenced by data being missing for some productindustry combinations in certain countries, and by business size and structure which can influence which industry a given business is classified within (especially in the case of large, multi-activity enterprises).

Furthermore, it is likely that cloud services are produced by firms classified in other industries such as communications. Indeed, the ONTSI annual report of ICT, Media and Audiovisual Sector shows that total turnover of "Data processing, hosting, and related services" in Spain amounted to over EUR 5 billion in 2017, this compares to a total of just EUR 1.4 billion shown by the Eurostat Business Services Statistics database.

Nevertheless, it is notable that the "computer programming, consultancy, and related activities" industry records around the same turnover of "data processing, hosting, and related activities" as it does in the "data processing, hosting, and related activities; web portals" industry. Furthermore, and as might be expected, firms in the latter industry appear firmly focussed on data processing activities. while in the former industry they also undertake significant computer games publishing and online software distribution activities. 
Figure 4. Turnover from narrow cloud-containing product categories, 2015-17

EUR billion and as a percent of total turnover in each industry, European Countries

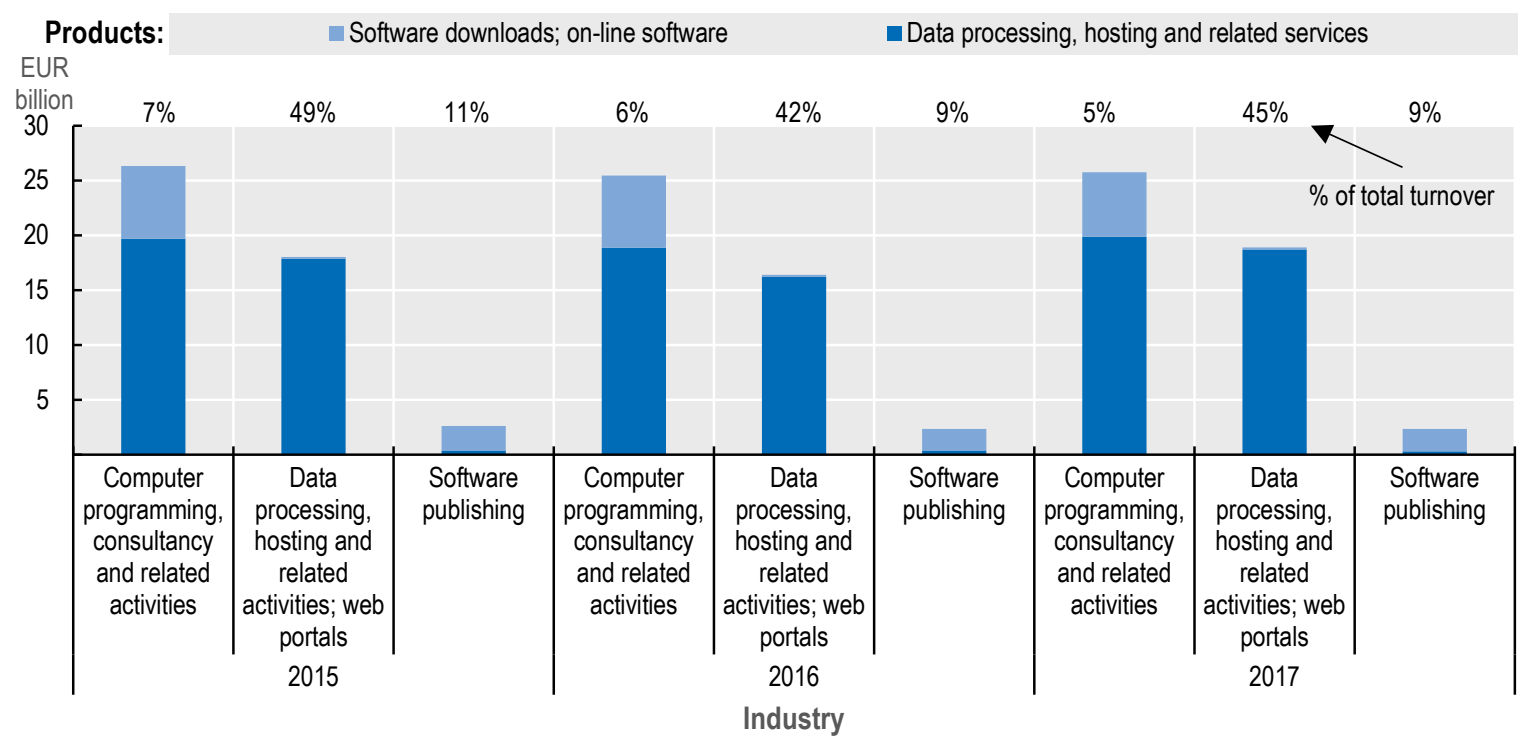

Note: Data cover 26 EU countries plus Norway; based on data availability (GBR is included). All industries producing the selected product categories are presented. For some countries, certain product-industry combinations are missing; columns include all available data but turnover shares are based only upon cases where a total and data for all three products are available.

Source: Eurostat Structural Business Statistics Database, August 2020.

In principle, it might be possible to use this supply-side information to adjust the use numbers in Figure 3 with the aim of more closely targeting the sub-products which contain cloud services. However, the Eurostat Structural Business Statistics database does not provide the necessary total and components of CPA 58 Publishing services so it is not possible to implement this approach to try to estimate the share of online software.

Nevertheless, sub-components are available for turnover in CPA J62-63 "Computer programming, consultancy and related services; Information services".

Table 3 presents turnover from CPA J63.11 "Data processing, hosting, and related services" as a share of turnover in CPA J63 "Information Services" over 2015-17. It shows that they make up the clear majority of revenue in the parent product class across all of these industries at around $70-90 \%$ (the other product class included in Information Services being J63.12 "Web portal services").

Comparing to the even broader "Computer programming, consultancy and related services; Information services" product class is a different story. Data processing, hosting, and related services generate the narrow majority (around 55-60\%) of turnover in the associated "Data processing, hosting and related activities; web portals" industry but only around 7$12 \%$ in the other industries presented. 
Table 3. Share of turnover from CPA J63.11 "Data processing, hosting, and related services" products (narrow) in turnover from J63 "Information Services" (broad) and J62-63

"Computer programming, consultancy and related services; Information services" (broad), by industry, 2015-17

Percentage and number of countries underlying each estimate, EEA countries

\begin{tabular}{|c|c|c|c|c|c|c|c|c|c|}
\hline & \multicolumn{3}{|c|}{2015} & \multicolumn{3}{|c|}{2016} & \multicolumn{2}{|c|}{2017} & \multirow[b]{2}{*}{$\begin{array}{r}\text { Number of } \\
\text { countries } \\
\text { contributing } \\
\text { to estimate }\end{array}$} \\
\hline Industry & $\begin{array}{r}\% \text { of } \\
\text { Information } \\
\text { Services } \\
\text { turnover }\end{array}$ & $\begin{array}{r}\% \text { of } \\
\text { Computer } \\
\text { programming } \\
\text {, consultancy } \\
\text { and related } \\
\text { services; } \\
\text { Information } \\
\text { services } \\
\text { turnover }\end{array}$ & $\begin{array}{r}\text { Number of } \\
\text { countries } \\
\text { contributing } \\
\text { to estimate }\end{array}$ & $\begin{array}{r}\% \text { of } \\
\text { Information } \\
\text { Services } \\
\text { turnover }\end{array}$ & $\begin{array}{r}\% \text { of } \\
\text { Computer } \\
\text { programming, } \\
\text { consultancy } \\
\text { and related } \\
\text { services; } \\
\text { Information } \\
\text { services } \\
\text { turnover }\end{array}$ & $\begin{array}{r}\text { Number of } \\
\text { countries } \\
\text { contributing } \\
\text { to estimate }\end{array}$ & $\begin{array}{r}\% \text { of } \\
\text { Information } \\
\text { Services } \\
\text { turnover }\end{array}$ & $\begin{array}{r}\% \text { of } \\
\text { Computer } \\
\text { programming, } \\
\text { consultancy } \\
\text { and related } \\
\text { services; } \\
\text { Information } \\
\text { services } \\
\text { turnover }\end{array}$ & \\
\hline $\begin{array}{l}\text { Computer } \\
\text { programming, } \\
\text { consultancy } \\
\text { and related } \\
\text { activities }\end{array}$ & $83 \%$ & $8 \%$ & 21 & $85 \%$ & $7 \%$ & 25 & $89 \%$ & $7 \%$ & 23 \\
\hline $\begin{array}{l}\text { Data } \\
\text { processing, } \\
\text { hosting and } \\
\text { related } \\
\text { activities; web } \\
\text { portals }\end{array}$ & $77 \%$ & $60 \%$ & 13 & $70 \%$ & $54 \%$ & 15 & $72 \%$ & $56 \%$ & 16 \\
\hline $\begin{array}{l}\text { Software } \\
\text { publishing }\end{array}$ & $92 \%$ & $12 \%$ & 15 & $88 \%$ & $11 \%$ & 16 & $86 \%$ & $9 \%$ & 17 \\
\hline
\end{tabular}

Note: Data relate to 26 EU countries plus Norway. Some product-industry combinations are not available in certain countries and years. Each given country and industry is included only when data are available for all of the necessary sub-products to be able to calculate the relevant totals (denominators), for this reason the number of countries underpinning each estimate varies.

Source: Eurostat Structural Business Statistics Database, August 2020.

These data could be used to estimate the extent to which narrow cloud-containing products contribute to the broader product groups, and the same shares applied to the data in Figure 3 to produce rough estimates of the consumption of these more specific cloud-containing product categories. Nevertheless, this approach would not overcome the fact that only narrow rather than specific cloud-containing product categories are available in the Eurostat structural business data and so various non-cloud products are included. Furthermore, such an approach would require strong assumptions - most notably that the share of these share of the relevant narrow cloud-containing products in turnover can be directly carried over to the use side, including to relevant categories of imported services. This is particularly questionable given that it can be observed that most of the major players in cloud services - especially in IaaS and PaaS are US companies (Dignan, 2019 $\mathrm{a}_{[7]}$ ) and hence cloud services would be expected to feature especially strongly in imports of information services (i.e. the domestic production of cloud services is likely to be a poor guide to the consumption of cloud services, except perhaps in the USA).

\section{United States}

The US Bureau of economic analysis publishes supply-use tables annually. In most years, these present a relatively condensed breakdown of 71 products. However, every five years, 
detailed supply-use tables present 405 product groups. Due to their relative importance, and the availability of more specific product categories, this analysis of US data will focus on cloud services within Information Services products. Figure 5 presents the available data, at the whole-economy level. Summary supply-use tables published each year provide the broad cloud-containing product category "Data processing, Internet publishing, and other information services" (which is roughly equivalent to "information services" in the OECD and Eurostat databases, as shown in Figure 2). Detailed supply-use tables, published every 5 years, provide the narrow category "Data processing, hosting, and related activities". The latest detailed tables available relate to 2012; the 2017 edition is due to become available in 2021.

The data show that the broad cloud-containing category has grown markedly over 20122018. This is in line with cloud services (and Information Services more generally) experiencing rapid uptake. It should be noted, however, that price changes have not been accounted for. It is likely that such services are becoming cheaper over time and so accounting for price changes would likely further exaggerate the growth seen.

Importantly, these data show that the narrow cloud-containing product category "Data processing, hosting, and related activities" comprised two-thirds $(66 \%)$ of the parent category "Data processing, Internet publishing, and other information services" in 2012. While this is the clear majority, it still suggests that considerable error is likely to be introduced by using broader aggregates as a proxy for cloud services use.

\section{Figure 5. Use of "Data processing, Internet publishing, and other information services" by businesses (broad), 2012-17}

United States; USD billions, current prices, purchasers' prices

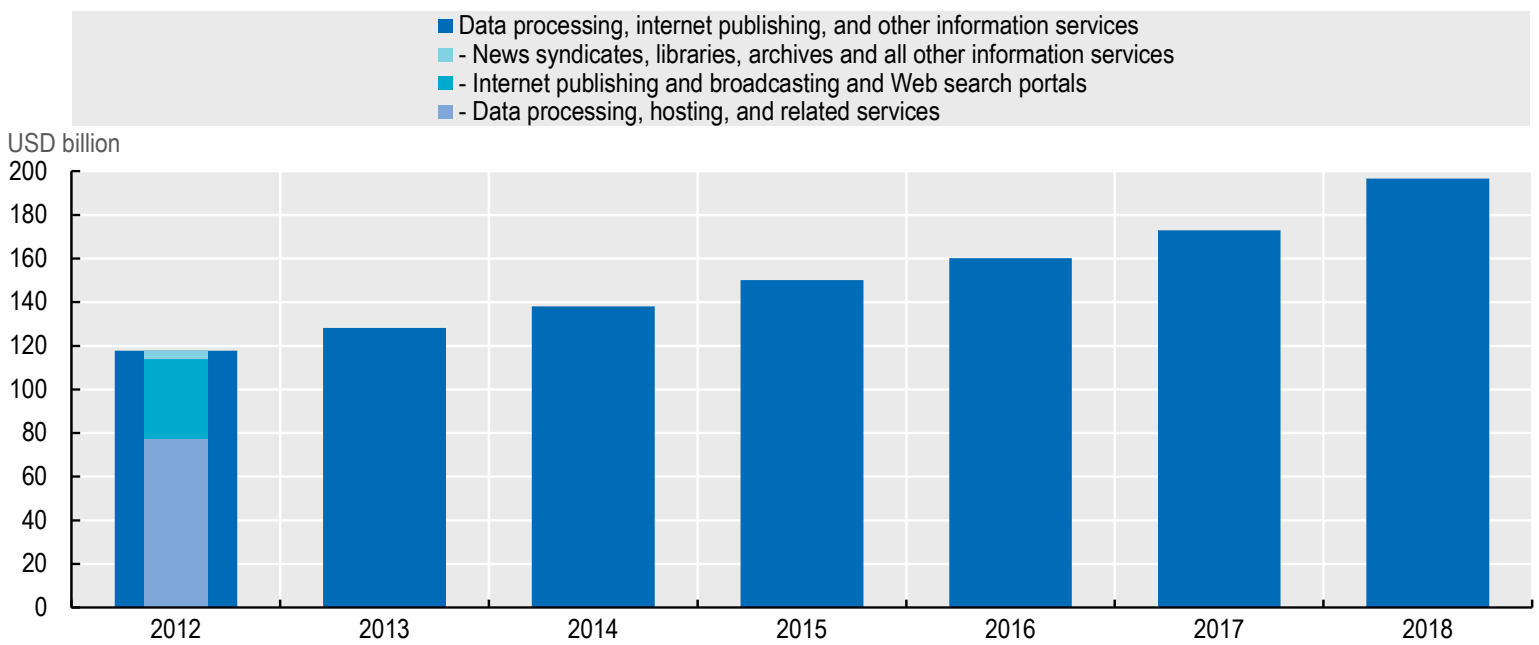

Note: Data processing, Internet publishing, and other information services" is a broad cloud-containing product category, "data processing, hosting, and web search portals" is the narrow cloud-containing product category therein. Data relate to intermediate use in the United States. Exports are excluded, as are amounts recorded as investment on the basis that cloud services are consumed as they are produced so can only be intermediate consumption.

Source: Bureau of Economic Analysis, Input-Output Accounts database, retrieved August 2020.

Figure 6 presents the 2012 use data broken down by industry group and shows that this overall pattern tends to be replicated across industries - with the narrow category "Data processing, hosting, and related activities" being significant, but by no means the only 
component of the "Data processing, Internet publishing, and other information services" products used in different industries.

The broad category, "data processing, Internet publishing, and other information services" is available in annual supply-use tables while the narrow cloud-containing category is available only in the detailed supply-use tables. It is therefore necessary to seek a way to estimate the share of the latter over time. The simplest approach is to assume that the share remains constant over time.

However, that approach assumes that the narrow category has grown precisely in-line with the broad category. That is not a completely unreasonable assumption - especially given the relative importance of the relevant narrow category within its parent category. However, it is also possible to use data available from the US Census Bureau Services Annual Survey (SAS), which provides annual estimated selected expenses for employer firms in different industries to estimate how the narrow category might have grown over the period. Figure 7 shows that the expenses category "data processing and other purchased computer services" significantly outgrew overall expenses on average over the period 2013-2017.

Figure 6. Use of "data processing, Internet publishing, and other information services" component products, by sector, 2012

United States; USD billions, purchasers' prices

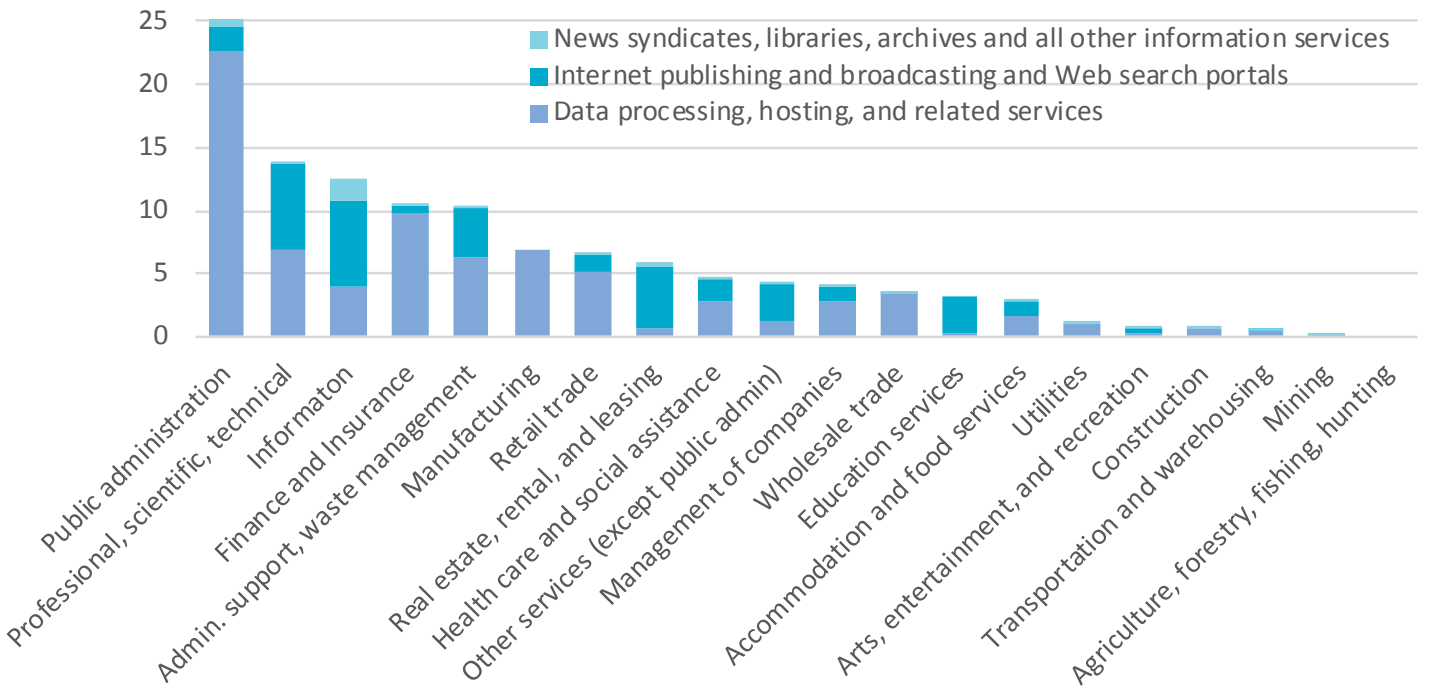

Note: Public administration includes defence.

Source: Bureau of Economic Analysis, Input-Output Accounts database, retrieved September 2019. 
Figure 7. Estimated expenses for employer firms, annual average growth, 2012-2017

United States, annual average growth rates

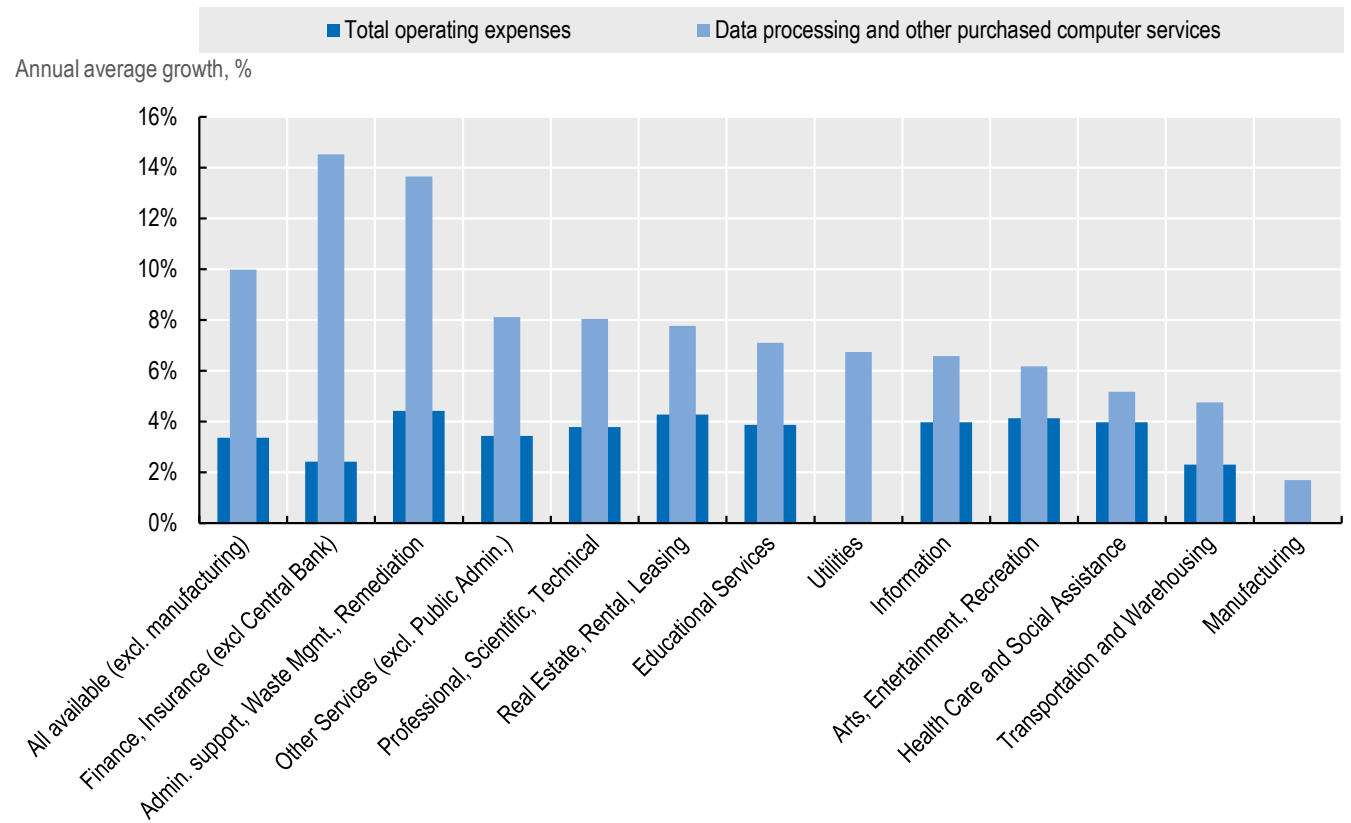

Note: For manufacturing, total operating expenses is unavailable, while the data processing and other purchased computer services figure for manufacturing is based on the period 2013 to 2018 ,

Source: 2017 Service Annual Survey data; 2013 and 2018 Annual Survey of Manufacturers

These annual average growth rates can be applied to the 2012 figures for use of "data processing, hosting, and related services" to provide alternative estimates for the period 2013-17. Figure 8 presents estimates based on both, the "2012 share" approach and the "growth-based approach". In general, there is not a great difference between the two sets of estimates, although the growth-based estimates are more often slightly lower.

There are two key exceptions though. Finance and insurance has the highest estimated average growth rate, at $15 \%$ per year and this results in an infeasible estimated value around one-third greater than the parent category total. By contrast, manufacturing has the lowest estimated annual average growth rate, at just $0.2 \%$. This leads to the growth-based estimate being around half the 2012 share-based estimate (for which the share was 100\%).

Given the relatively small differences between the two approaches, in most industries, plus advantages in terms of industry coverage and the impossibility of gaining infeasible results, the 2012 share-based approach seems most desirable. However, such an approach has clear limitations and should be regarded as providing only rough estimates. 
Figure 8. Estimated "data processing, hosting and related services" (narrow) within use of "data processing, Internet publishing, and other Information services (broad), 2017

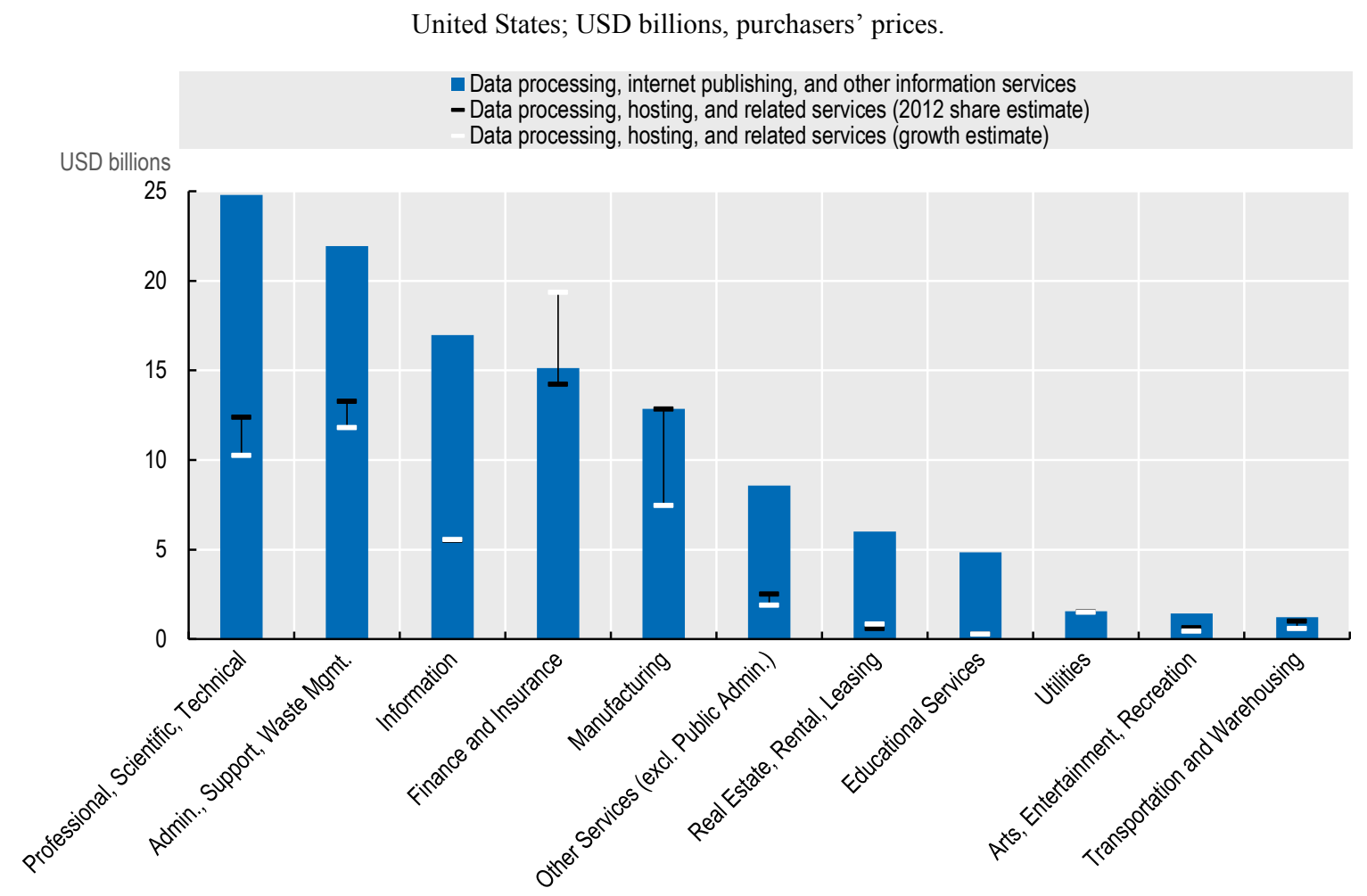

Note: Only industries for which the data needed to derive growth-based estimates are presented. For manufacturing, the growth rate is based on 2013-2018.

Source: Based on 2017 supply-use tables, 2012 detailed supply-use tables, Services Annual Survey 2013-2017, Annual Survey of Manufactures 2013 and 2018.

Furthermore, it remains the case that even the narrow cloud-containing product category "Data processing, hosting, and related activities" contains various product sub-categories other than the specific cloud-containing categories identified. As shown in Figure 2, these include colocation, data processing and management, information transformation, and streaming services. It is therefore desirable to seek additional detailed data that can be used to try to estimate the share of specific cloud-containing categories more closely.

The US Economic Census product line data, a key source underpinning the detailed supplyuse tables, provide a wealth of additional detail, though unfortunately these relate to business sales revenues and receipts (i.e. supply-side data) rather than expenditures on buying relevant product categories (i.e. use-side data). Nevertheless, sales receipts (i.e. supply-side) data are available at the level of specific cloud-containing product categories. These data are presented in Table 4, which shows that sales receipts for specific cloudcontaining product categories were worth about USD 48 billion in 2012. The relevant receipts were concentrated in the "Information" sector (USD $42 \mathrm{bn}$ ) and especially in the "data processing, hosting, and related services" subsector (USD $40 \mathrm{bn}$ ), with a further portion (USD $6.2 \mathrm{bn}$ ) in the "Professional, scientific, and technical services" industries. 
Table 4. Sales receipts from specific cloud-containing product categories, United States, 2012

USD billion.

\begin{tabular}{lccccc}
\hline & $\begin{array}{c}\text { Total } \\
\text { specific } \\
\text { cloud- } \\
\text { containing } \\
\text { categories }\end{array}$ & $\begin{array}{c}\text { Web site } \\
\text { hosting } \\
\text { services* }\end{array}$ & $\begin{array}{c}\text { Application } \\
\text { service } \\
\text { provisioning }\end{array}$ & $\begin{array}{c}\text { Data } \\
\text { storage } \\
\text { services }\end{array}$ & $\begin{array}{c}\text { Other data } \\
\text { processing } \\
\text { or } \\
\text { infrastructure } \\
\text { provisioning } \\
\text { services }\end{array}$ \\
\hline All industries producing specific cloud- & 48 & 14 & 29 & 2.4 & 2.4 \\
containing product categories & & & & & \\
Information & 42 & 13 & 25 & 1.6 & 2.4 \\
- Software publishers & 0.7 & - & 0.7 & & \\
- Data processing, hosting, and related services & 40 & 12 & 24 & 1.6 & 2.4 \\
- Internet publishing and broadcasting & 0.4 & 0.4 & - & & \\
- Web search portals & 0.02 & 0.02 & - & & \\
Professional, scientific, and technical services & 6.2 & 1.3 & 4 & 0.8 & \\
- Computer systems design and related services & 6.2 & 1.3 & 4 & 0.8 & \\
-- Custom computer programming services & 2.9 & 0.7 & 2 & 0.2 & \\
-- Computer systems integrators & 1.2 & 0.2 & 0.8 & 0.2 & \\
--Computer systems consultants (except & 0.1 & 0.01 & 0.02 & 0.02 & \\
computer systems integrators) & 1.4 & 0.1 & 1.1 & 0.1 & \\
- Computer facilities management services & 0.7 & 0.3 & 0.07 & 0.3 & \\
- Other computer related services & & & & & \\
\hline
\end{tabular}

Note: *with or without integration of related services.

All industries with receipts from the relevant specific cloud-containing product categories are presented.

These product categories will likely include services not based on cloud architecture/infrastructure. Excluding these would require further detail on the precise nature of the underlying computer infrastructure.

Source: United States Census Bureau, Economic Census 2012.

Table 5 compares sales receipts in those specific cloud-containing product categories to the narrow and broad cloud-containing aggregates. They comprise almost half of receipts for products covered by the broad category "data processing, Internet publishing and other information services" (USD 99 billion). They comprised 67\% of receipts for products covered by the narrow category "Data processing, hosting, and related services" (USD 70 billion). Furthermore, in several sub-industries, receipts for both the broad and narrow cloud-containing product categories almost totally relate to the underlying specific product categories.

It is worth noting, however, that the supply of "Data processing, hosting, and related services" products recorded in the 2012 detailed supply-use tables amounts to USD 111 billion, with only a small fraction being imported (USD 325 million). That amount is markedly greater than the USD 70 billion of receipts recorded by the industries presented here, though it will incorporate adjustments to move from business receipts data to National Accounts concepts and imputations to produce an exhaustive estimate (including ownaccount production and any production in additional industries e.g. communication). 
Table 5. Sales receipts from specific cloud-containing product categories, and shares of parent product categories, United States, 2012

USD billion.

\begin{tabular}{|c|c|c|c|c|c|c|}
\hline \multirow[b]{2}{*}{ PRODUCING industry (NAICS) } & \multirow[b]{2}{*}{$\begin{array}{l}\text { Total } \\
\text { specific } \\
\text { cloud- } \\
\text { containing } \\
\text { categories } \\
\text { (a) }\end{array}$} & \multicolumn{2}{|c|}{$\begin{array}{c}\text { Narrow cloud-containing } \\
\text { product category }\end{array}$} & \multicolumn{2}{|c|}{$\begin{array}{l}\text { Broad cloud-containing } \\
\text { product category }\end{array}$} & \multirow[b]{2}{*}{ All products } \\
\hline & & $\begin{array}{l}\text { Data } \\
\text { processing, } \\
\text { hosting, and } \\
\text { related } \\
\text { services } \\
\text { (b) }\end{array}$ & $\begin{array}{c}\text { Share } \\
(\mathrm{a} / \mathrm{b}) \\
\%\end{array}$ & $\begin{array}{l}\text { Data } \\
\text { processing, } \\
\text { Internet } \\
\text { publishing, } \\
\text { and other } \\
\text { information } \\
\text { services } \\
\text { (c) }\end{array}$ & $\begin{array}{c}\text { Share } \\
(\mathrm{a} / \mathrm{c}) \\
\%\end{array}$ & \\
\hline $\begin{array}{l}\text { All industries producing specific cloud- } \\
\text { containing product categories }\end{array}$ & 48 & 70 & 69 & 99 & 48 & 2718 \\
\hline Information & 42 & 64 & 66 & 93 & 45 & 1238 \\
\hline - Software publishers & 0.7 & 0.7 & 100 & 0.7 & 100 & 171 \\
\hline $\begin{array}{l}\text { - Data processing, hosting, and related } \\
\text { services }\end{array}$ & 40 & 63 & 63 & 63 & 63 & 108 \\
\hline - Internet publishing and broadcasting & 0.4 & 0.4 & 100 & 28 & 1.4 & 54 \\
\hline - Web search portals & 0.02 & 0.02 & 100 & 0.8 & 2.5 & 34 \\
\hline Professional, scientific, and technical services & 6.2 & 6.4 & 97 & 6.4 & 97 & 1480 \\
\hline $\begin{array}{l}\text { - Computer systems design and related } \\
\text { services }\end{array}$ & 6.2 & 6.4 & 97 & 6.4 & 97 & 326 \\
\hline -- Custom computer programming services & 2.9 & 3.0 & 97 & 3.0 & 97 & 121 \\
\hline -- Computer systems integrators & 1.2 & 1.2 & 100 & 1.2 & 100 & 124 \\
\hline $\begin{array}{l}\text {--Computer systems consultants (except } \\
\text { computer systems integrators) }\end{array}$ & 0.1 & 0.1 & 100 & 0.1 & 100 & 28 \\
\hline - Computer facilities management services & 1.4 & 1.5 & 100 & 1.5 & 100 & 34 \\
\hline - Other computer related services & 0.7 & 0.7 & 100 & 0.7 & 100 & 18 \\
\hline
\end{tabular}

Note: All industries with receipts from the relevant specific cloud-containing product categories are presented. These product categories will likely include services not based on cloud architecture/infrastructure. Excluding these would require further detail on the precise nature of the underlying computer infrastructure.

Source: United States Census Bureau, Economic Census 2012.

Even so, if one is willing to accept the (strong) assumption that the share of specific cloudcontaining product categories in the parent narrow (69\%) and broad (48\%) categories is the same across time these shares can be used to attempt to adjust the use-side data to more closely target cloud services (Figure 9).

However, there are clearly very strong limitations associated with this approach. Firstly, taking more detailed information from the supply-side and applying that to the use-side, assumes that specific cloud-containing product categories comprise the same share (48\%) of use of the (broad) parent category regardless of industry. This ignores the varied propensity to use the narrow cloud-containing product category "data processing, hosting, and related services", seen in Figure 6.

Furthermore, extending this approach over time makes the assumption that the use of specific cloud-containing product categories has grown only at the same rate as the broad parent category. Until the next set of detailed supply-use tables become available in 2021, it will not be possible to assess the validity of this assumption. 
Figure 9. Estimated share of specific cloud-containing product categories in "data processing, Internet publishing, and other information services" use, United States, 2012-2018

USD billion, current prices, purchasers' prices.

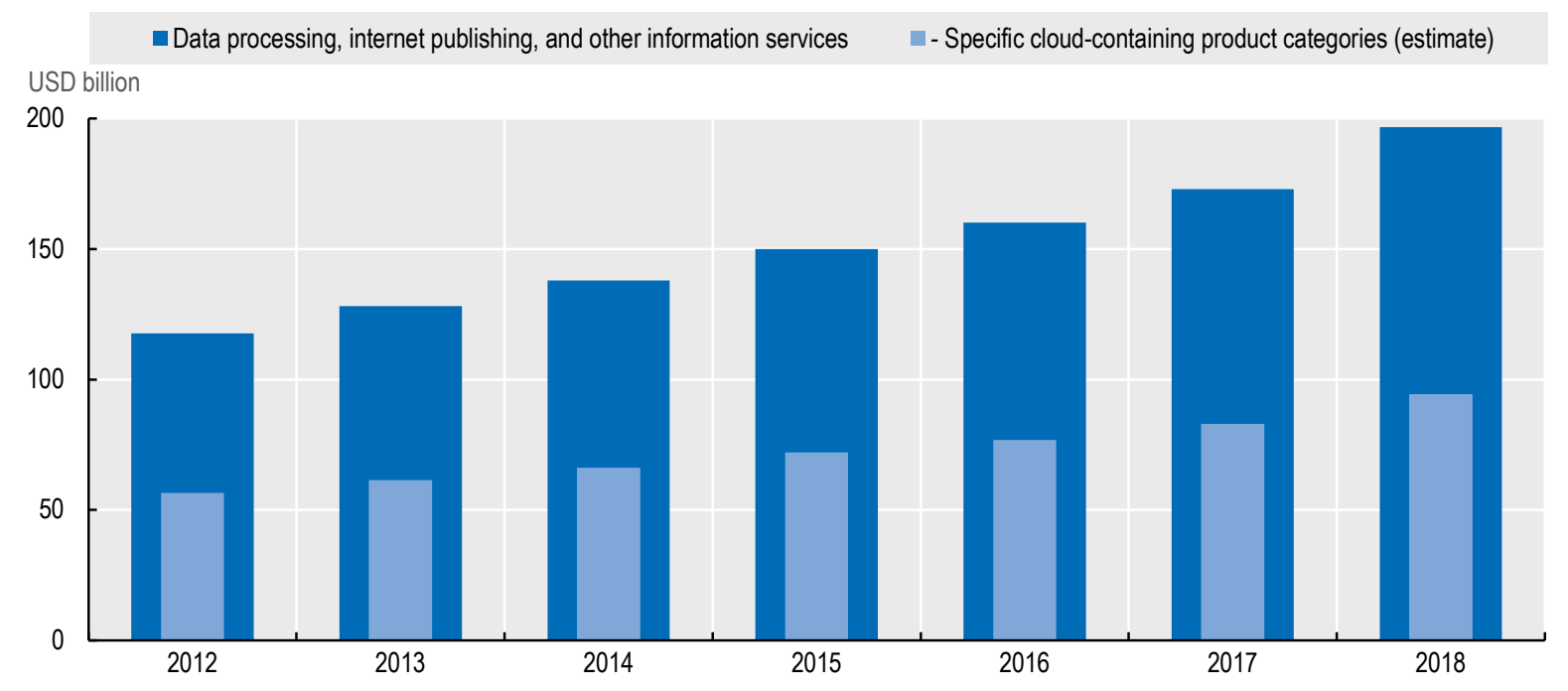

Note: Estimate based on the total share of "website hosting services", "application service provisioning", "data storage services", and "other data processing or IT infrastructure provisioning services" within "data processing, Internet publishing, and other information services", whole-economy level (48\%).

Source: Based on United States Census Bureau, Economic Census 2012 and Bureau of Economic Analysis input-output database, October 2020.

\section{Canada}

The Canadian version of NAPCS sets out individual specific cloud-containing product categories, and, as shown in Figure 2, even sets out a split of "application service provisioning" based on whether a cloud service model is used or not.

However, data do not (yet) seem to be available at this level of detail. The annual Canadian supply-use tables go down to the narrow cloud-containing product category - "data processing, hosting, and related activities". Figure 10 presents this category for the period 2012-2016 as well as the industry breakdown for 2016. Overall, the rate of growth appears similar to the USA and the top industries using these products are generally similar. 
Figure 10. Intermediate use of "Data processing, hosting and related services", Canada, 2012-2016,

CAD billion, current prices, purchasers' prices.

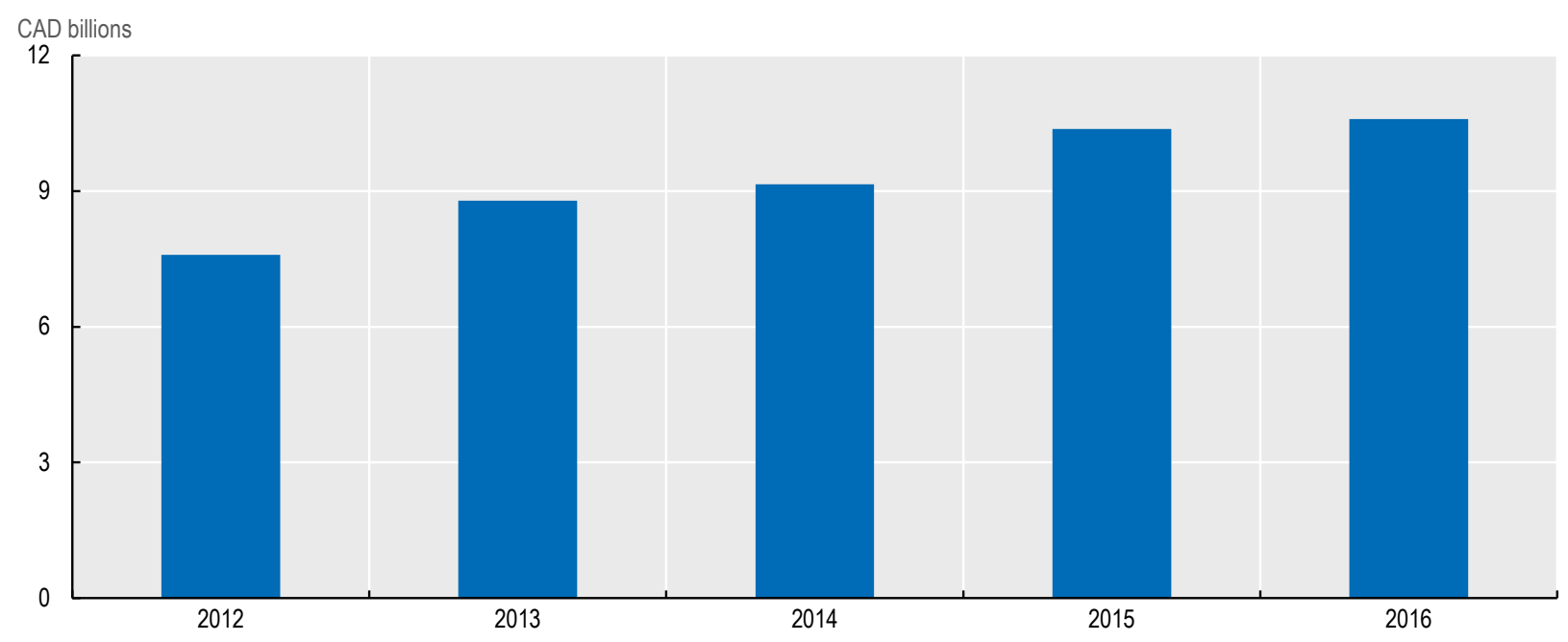

Source: Exports are excluded, as are amounts recorded as investment on the basis that cloud services are consumed as they are produced so can only be intermediate consumption when purchased by businesses. Source: Statistics Canada, Supply and Use Tables 2012-2016.

Although figures for this narrow category are published each year, more detailed supplyuse tables do not appear to be available intermittently (as they are in the USA). The only source for further information appears to be data from the "Annual Survey of Service Industries: Software Development and Computer Services", which gives additional detail on sales revenues from "Hosting and information technology infrastructure provisioning". Although that is still a narrow rather than a specific cloud-containing product category, it is a more specific sub-category within the "Data processing, hosting, and related services" product category (Table 6).

On average, between 2013 and 2018, "Hosting and information technology infrastructure provisioning" comprised just over $50 \%$ of sales by firms in the "Data processing, hosting, and related services" industry. This share seems to have an upward trend but also appears subject to other causes of variation (e.g. sampling variation).

For comparison, "Hosting and IT infrastructure provisioning services" can be estimated for the USA using the economic census product line data presented in Table 4 as well as relevant lines for the additional non-cloud-containing specific product categories the category includes (see Figure 2). In the USA, "Hosting and IT infrastructure provisioning services" comprised $57 \%$ of total sales receipts of the "Data processing, hosting, and related services" industry in 2012. This is similar to, but on the high end of, the shares in Canada between 2013-2017 (the Canadian data do not go back as far as 2012). 
Table 6. Sales receipts for narrow cloud-containing product categories, Canada, 2013-2018

As a percentage of total sales.

\begin{tabular}{|c|c|c|c|c|c|}
\hline & & & $\begin{array}{l}\text { Narrow cloud- } \\
\text { containing product } \\
\text { category }\end{array}$ & $\begin{array}{l}\text { Narrow cloud- } \\
\text { containing product } \\
\text { category }\end{array}$ & \\
\hline $\begin{array}{l}\text { Producing industry } \\
\text { (NAICS) }\end{array}$ & & $\begin{array}{c}\text { All products } \\
\%\end{array}$ & $\begin{array}{l}\text { Data processing, } \\
\text { hosting, and related } \\
\text { services } \\
\% \text { (a) }\end{array}$ & $\begin{array}{l}\text { Hosting and } \\
\text { information } \\
\text { technology (IT) } \\
\text { infrastructure } \\
\text { provisioning } \\
\% \text { (b) }\end{array}$ & $\mathrm{b} / \mathrm{a}$ \\
\hline \multirow{6}{*}{$\begin{array}{l}\text { Data processing, } \\
\text { hosting, and related } \\
\text { services }\end{array}$} & 2018 & 100 & 88.6 & 54.4 & 61 \\
\hline & 2017 & 100 & 89.7 & 52.9 & 59 \\
\hline & 2016 & 100 & 92.7 & 55.1 & 59 \\
\hline & 2015 & 100 & 91.3 & 53.8 & 59 \\
\hline & 2014 & 100 & 89.9 & 45.3 & 50 \\
\hline & 2013 & 100 & 86.0 & 43.2 & 50 \\
\hline \multirow{6}{*}{$\begin{array}{l}\text { Computer systems } \\
\text { design and related } \\
\text { services }\end{array}$} & 2018 & 100 & 5.6 & & \\
\hline & 2017 & 100 & 6.3 & na & - \\
\hline & 2016 & 100 & 6.5 & na & - \\
\hline & 2015 & 100 & 6.6 & na & - \\
\hline & 2014 & 100 & 6.4 & na & - \\
\hline & 2013 & 100 & 6.3 & na & - \\
\hline Software publishers & $2013-17$ & 100 & $\begin{array}{r}\text { Produced but share } \\
\text { suppressed due to } \\
\text { disclosure }\end{array}$ & na & - \\
\hline
\end{tabular}

Note: The "Software publishers" industry also records sales of "data processing, hosting, and related services", however these are suppressed in the data due to confidentiality requirements. Data are available as percentages as presented, the underlying figures are not published.

Source: Statistics Canada. Table 21-10-0210-01 Software development and computer services, breakdown of sales.

However, in the US data, "Hosting and IT infrastructure provisioning services" is around $50 \%$ greater than the specific cloud-containing product categories alone - and so does not itself seem to be a good proxy for the latter. If one were to treat it as such by adjusting the figures in Table 6 to express them as a share of the parent category ("b/a" column), the figure for Canada appears to be lower than the USA's 63\% in 2012, at around 56\% on average over the period 2013-2018. Nevertheless, if the wider scope of the numerator in the Canadian estimate could be accounted for, the result would likely be considerably lower - the US data suggest around one-third less i.e. around 37\%. This is not necessarily unreasonable, as the United States appears to have relative specialisation in cloud services so specific cloud-containing product categories might be expected to be a relatively larger share of "data processing, hosting, and related services" sales receipts in the USA than in other countries.

However, it must be recalled that this calculation and comparison is possible only for the "data processing, hosting, and related services industry". The sub-category "hosting and IT infrastructure provisioning" is not available for the other industries which record sales of the parent category. Nor for the several other industries which the Canadian supply tables show to also produce "Data processing, hosting, and related services" products. It is therefore not possible to use these figures to produce an equivalent of the $69 \%$ US share of specific cloud-containing product categories in sales receipts for "data processing, 
hosting and related services" across all industries producing the relevant product categories. The estimate for the "data processing, hosting, and related services industry" is unlikely to be generalizable given that industry's relative specialisation in the relevant cloudcontaining product categories.

\section{Other OECD countries}

In Australia, supply-use tables are published annually, with 2017 being the most recent available year at the time of writing. In New Zealand, SUTs are published every five years, with 2013 being the latest available. In both cases, it appears that the relevant cloudcontaining product categories are subsumed within very broad aggregates. In the case of Australia, they will be within the wide product group "Internet Service Providers, Internet Publishing and Broadcasting, Websearch Portals and Data Processing", while in the New Zealand tables they are likely to be within "Computer software and services". No additional sources were flagged by WPMADE delegates

For Chile, a search of the National Statistics Office website did not find Supply-Use tables.

For Israel, a search of the CBS website found Input-Output tables only up to 2006.

The Japan service areas of product classification (MIC, 2019 $[17]$ ) is the only one of those analysed which systematically delineates IaaS, PaaS, and SaaS. However, the classification was finalised in 2019 and will be used in the 2020 Economic Census. The Japanese Input-Output tables, the latest available of which relates to 2015, includes the category "Internet-based services", which is the broad category containing cloud services. Categories to be used in the 2020 tables were under discussion at the time this paper was being drafted.

For Korea, searching the English language KOSIS site did not yield supply-use tables or data on production or sales by product.

For Mexico, the most recent Supply-Use tables were released in 2013. Furthermore, INEGI has confirmed that detailed breakdowns are not available, as they are not collected in the underlying Economic Census or Surveys.

Turkey participates in the European Statistical System. However, the relevant data are not available on the Eurostat website.

\section{Seeking further data}

Data availability appears sparse even for the broad cloud-containing product category "Information Services" and even more rare at levels of greater detail. One reason for this is likely to be that in some cases the underlying business surveys do not collect the relevant detail and so it is not available at all. Another likely scenario is that, where these details are collected, the individual specific cloud-containing product classes are not deemed disclosive and/or insufficiently robust due to sample sizes or other quality control factors.

As a proposed way around the latter, and following discussion of this work at the WPMADE meeting in November 2019, the OECD Secretariat arranged a data collection through which countries could provide whatever detail are able. This included aggregates of all the specific cloud-containing product classes summed together, which could be provided even when individual sub-components needed to be suppressed. 
In order to encourage the provision of any available data, this collection was intentionally not too prescriptive about the sources or measures to be used. Nevertheless, respondents were asked to privilege supply-side or expenditure data where available. Several countries provided links or files of supply-use data rather than completing forms.

As a result, the data received varied in precisely what was measured as well as the detail available (i.e. how close they get to the specific cloud-containing product categories). Nevertheless, input was received from 12 WPMADE participating countries although several contributions were, unfortunately, not compatible with the analysis at hand - due to not covering/identifying Information Services products or to covering only a small subset of the business sector central to this analysis (e.g. public bodies, including public corporations).

Of the responses received, the slight majority related to the supply-side (i.e. revenues from the sale of relevant products. Only a very small subset of countries provided any estimate for "total specific cloud-containing product classes" and several of those appear likely to be somewhat incomplete. As such, a key conclusion that can be drawn is that, even when statistical issues such as small cell sizes are mitigated, estimates of total specific cloudcontaining products do not appear to be readily computable for many countries. In many cases this is likely to be due to the need to isolate sub-sections of the "Other hosting and IT provisioning services" product line in order to remove parts which are clearly not cloud services.

\section{Use data}

On the use-side, several countries provided figures for either "Information Services" (broad) or "Data processing, hosting, and related services" (narrow). These are shown in Figure 11.

The first thing this gives is further evidence of the share that use of "Information Services" comprises within the more widely-available "Computer programming, consultancy, and related services; Information services" aggregate. This is combined with the other use-side data available from the OECD supply-use database in Table 7, which shows that the average (mean) share across the available countries and periods was $23 \%$, with quartiles of $13 \%$ and $31 \%$.

In addition, one country provided even more detail reaching the narrow level of cloudcontaining product categories. In Canada, "Data processing, hosting, and related services" comprised one third (33\%) of Information Services use on average across 2016 and 2017. Canada also provided data points for use of on-line software, which amounted to USD 0.8 billion in 2016 and 1.1 billion in 2017. 
Figure 11. Use: additional breakdowns within intermediate consumption of "Computer programming, consultancy, and related services; Information services"

USD billion, current prices

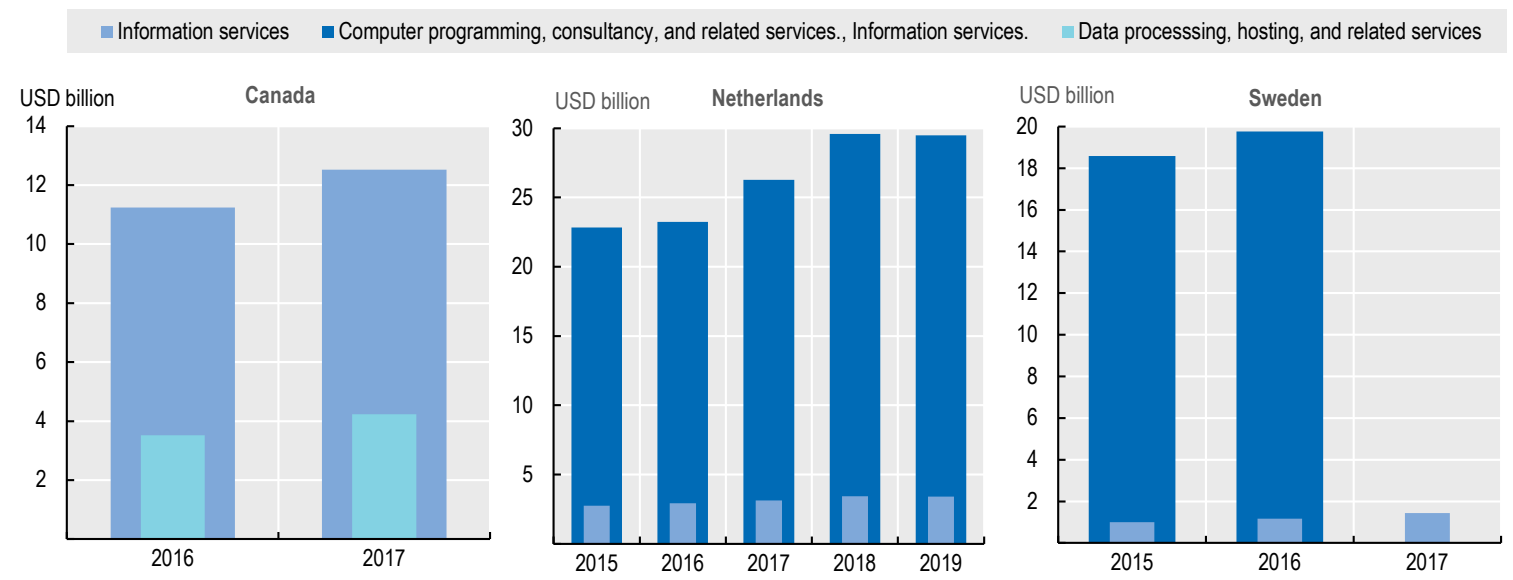

Note: For Sweden, the figures for "Computer programming, consultancy, and related services; Information services" come from the OECD supply-use database.

Source: OECD supply-use database and national submissions.

Table 7. Use of "Information Services" products as a share of "Computer programming, consultancy, and related services; Information services"

Based on available data presented in this paper.

\begin{tabular}{rcrl}
\hline \multicolumn{1}{c}{ Country } & Period & Average & Source \\
\hline AUS & $2012-2017$ & $29 \%$ & OECD use at purchasers' prices database \\
BEL & $2012-2016$ & $38 \%$ & OECD use at purchasers' prices database \\
CAN & $2012-2014$ & $32 \%$ & OECD use at purchasers' prices database \\
CZE & $2012-2019$ & $24 \%$ & OECD use at purchasers' prices database \\
KOR & $2015-2017$ & $23 \%$ & OECD use at purchasers' prices database \\
MEX & 2013 & $5 \%$ & OECD use at purchasers' prices database \\
NLD & $2015-2019$ & $12 \%$ & CBS Supply and use by products of activity database \\
SWE & $2015-2016$ & $6 \%$ & SWE submission and OECD use at purchasers' prices database \\
SVK & $2015-2016$ & $16 \%$ & OECD use at purchasers' prices database \\
USA & $2012-2016$ & $41 \%$ & OECD use at purchasers' prices database \\
MEAN & & $23 \%$ & \\
MEDIAN & & $13 \%$ & \\
Q1 & $31 \%$ & \\
Q3 & &
\end{tabular}

Source: OECD use at purchasers' prices database and national submissions.

Unfortunately, the countries in Figure 11 could not could not provide detail down to the level of specific cloud-containing product categories. Nevertheless, Australia was able to provide a total and breakdown for specific cloud-containing products. This comes with the caveat that the figures provided cover "IOPC 59210020 Data processing and web hosting services" and "IOPC 59220010 Information storage and retrieval services", which may not precisely align with the product categories selected in Section 3. . In particular, there is no counterpart for the category "Other data processing or IT infrastructure provisioning services", though these activities may well be included in the other categories available. 
Indeed, the ABS advised that "the existing product definitions include activity other than pure 'web hosting services"'

The figures are presented in Figure 12, which shows that intermediate consumption of specific cloud-containing products totalled USD 7 billion in Australia in 2017, and comprised around 38\% of intermediate consumption of information services in both 2016 and 2017. The share in 2013-2017 was markedly lower (11-22\%) leading to an average over $2013-17$ of $25 \%$.

Figure 12. Use: Total intermediate consumption of specific cloud-containing product classes, Australia, 2013-2017

USD billion, current prices.

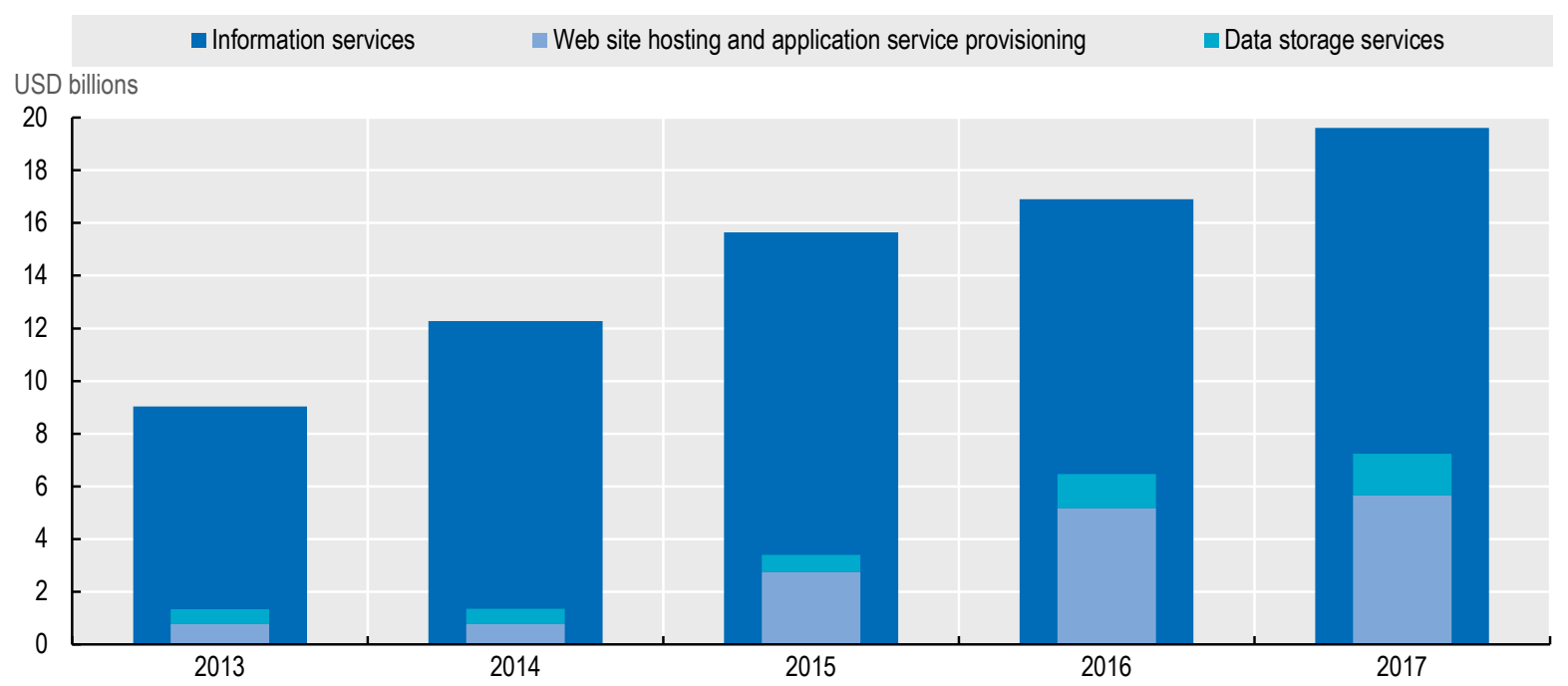

Note: Figures provided cover "IOPC 59210020 Data processing and web hosting services" and "IOPC 59220010 Information storage and retrieval services", which may not precisely align with the product categories selected in section 3. . Indeed, the ABS advised that "The existing product definitions include activity other than pure 'web hosting services"'

Source: Submission by Australia, November 2020.

In addition, the Russian Federation provided data on "Enterprises expenditure on cloud services", as presented in Figure 13. This was collected through a special module included on the "Usage of Information and Communication Technologies and Production of Hardware and Software and Rendering ICT Services" survey for 2016 - 2018. The module asked for "the enterprise's actual expenses in monetary form" and included the breakdown "of which cloud services" within the category "ICT services of external enterprises and consultants (except telecommunication services and training)".

This shows that businesses in the Russian Federation spent around 250-300 million USD on cloud services in $2017 / 18$, with around $10 \%$ of this demand coming from firms in the ICT sector. However, business expenditure on the parent product classes is not available in the OECD Supply-use tables database, nor on the (English language) Federal State Statistics Service website so it is not known what share of those relates to cloud services and so the share in total Information Services expenditure could not be computed. 
Figure 13. Enterprise expenditure on cloud services, Russian Federation

USD millions, 2017-2018

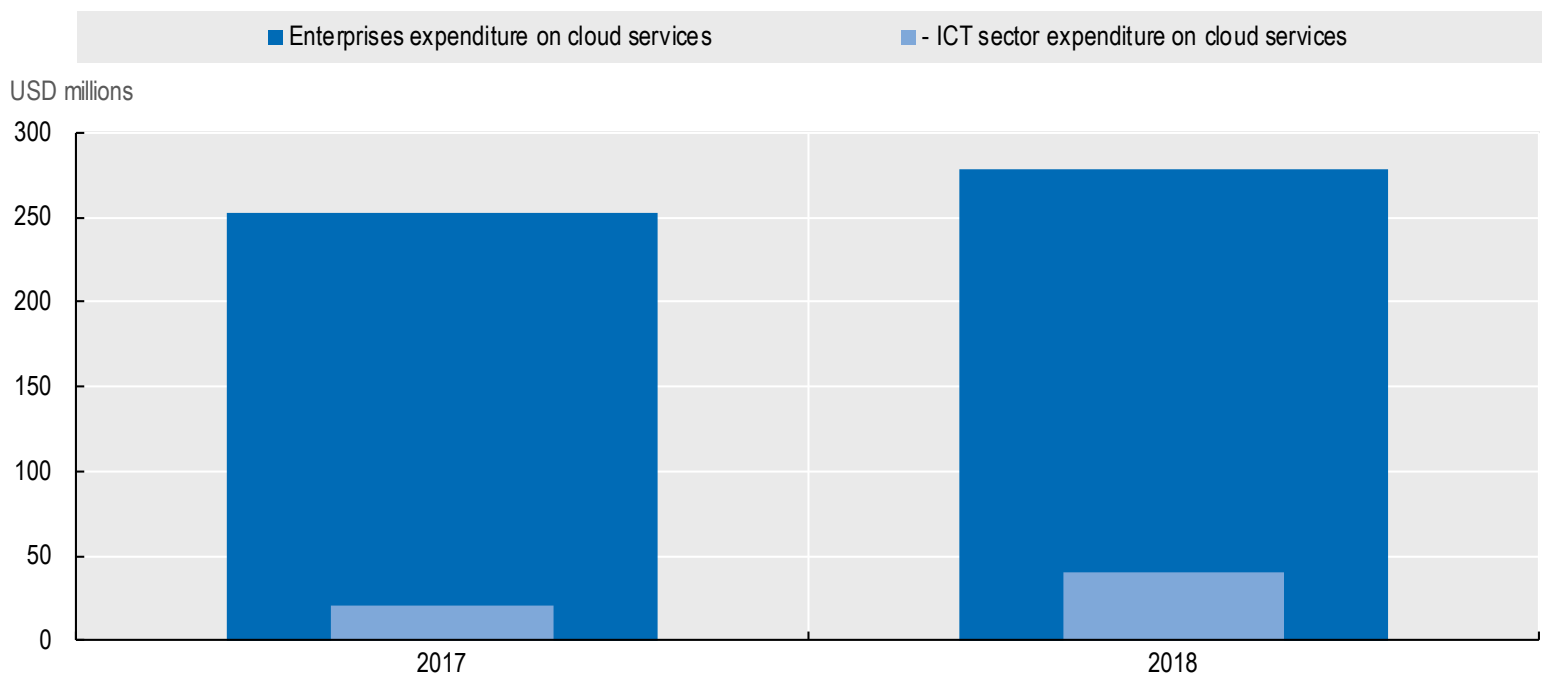

Source: Submission by Russian Federation.

\section{Supply data}

In addition to the use data showcased above, several countries also provided data on the supply of cloud-containing product classes. However, in many cases the additional detail does not go beyond the level of broad cloud-containing product classes, as shown in Figure 14. This shows that, of the countries shown Germany, the United Kingdom, and Canada produce the most of these services, worth around 8-18 billion USD. Nevertheless, it appears that all these countries together produce at most around one third as much of these products as the United States, which produced USD 111 billion in 2012 (a volume that has surely increased significantly since although this cannot be assessed until the 2017 Economic Census product line data and/or 2017 detailed supply-use tables are published).

Figure 14. Data processing, hosting, and related services, 2012-2018

Turnover/total output, current prices.

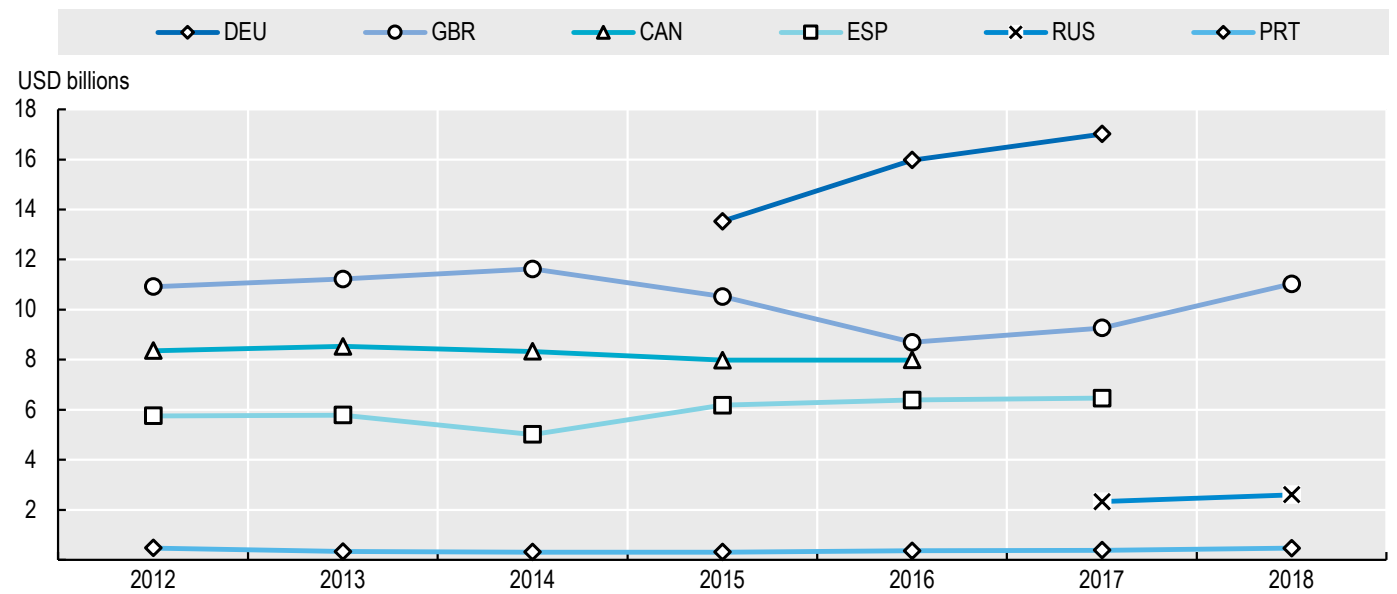

Source: OECD based on national submissions. 
Some countries also provided further information within "data processing, hosting, and related services" but disaggregating the "Other hosting and IT provisioning services" to isolate only the parts that are specific cloud-containing products does not generally appear to be possible.

Nevertheless, Spain shared that they have collected a separate product category not prescribed in the CPA - "Cloud and SaaS solutions (Software as a Service)" - in business questionnaires since 2016. The data collected suggest that cloud services make up a relatively small share of the overall product class - up to $7 \%$ and $5 \%$ on average.

Figure 15. Sub-components of "Data processing, hosting, and related services" turnover, Spain, 2016-2018

EUR billions

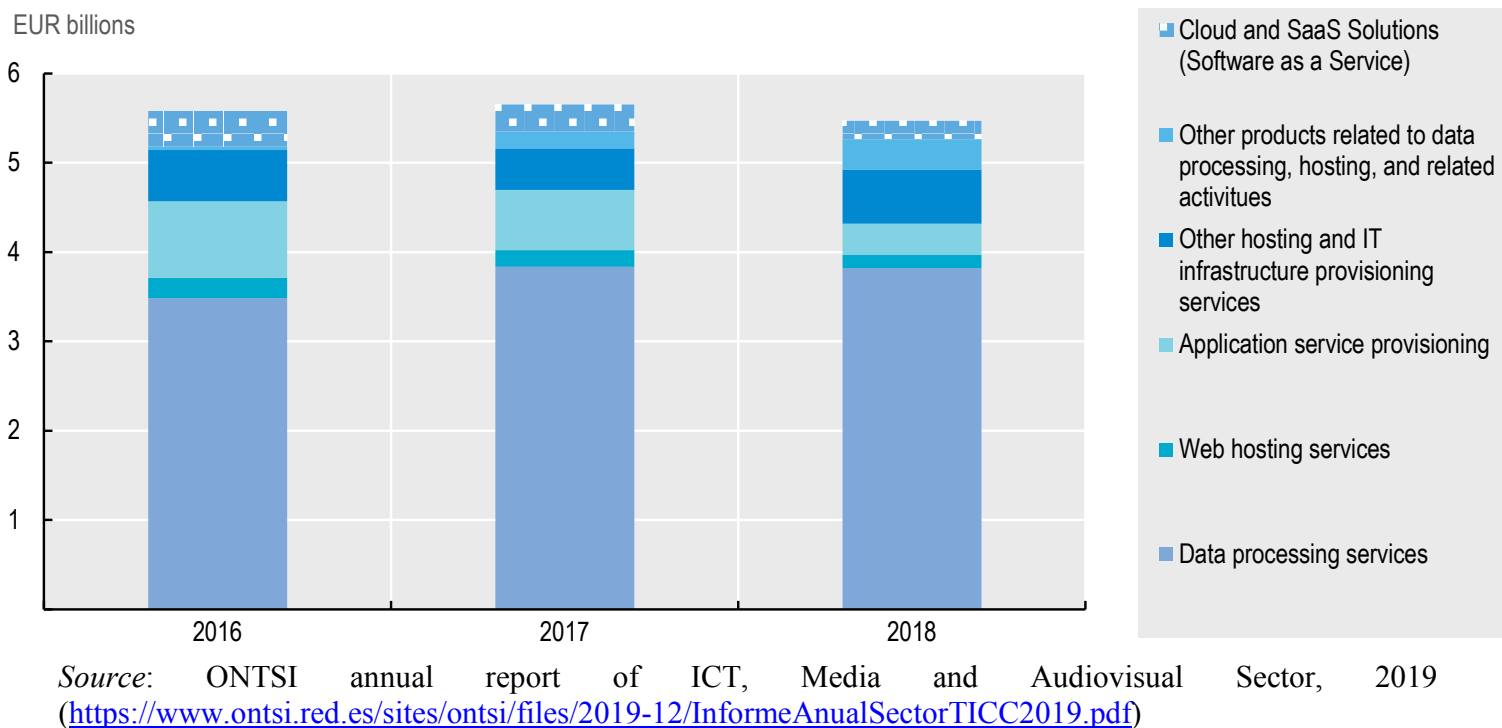

(https://www.ontsi.red.es/sites/ontsi/files/2019-12/InformeAnualSectorTICC2019.pdf)

However, the report notes several limitations of the data currently. Firstly, it is very difficult to determine what percentage of the products identified relate to Cloud Computing, except in the case of the category specifically for "Cloud and SaaS solutions". As such, it is very likely that, in many cases, companies have included Cloud Computing Services in another category. On this basis, including the two specific cloud-containing product classes "web hosting services" and "application service provisioning" leads to an average share in the parent product class of $20 \%$ across these three years.

The report also notes that the data cover companies headquartered in Spain, both Spanish and subsidiaries of foreign companies. As such, the cloud services revenue generated by companies based outside Spain but from customers in Spain is not included.

The data found/received are patchy and detail down to the level of specific cloudcontaining products or cloud service products specifically is rarely available. This points to the need for sustained effort across countries to improve the information collected and published in this area. 


\section{Estimating the use of specific cloud-containing product categories in other countries}

As shown above full use-side information on purchases of specific cloud-containing products by businesses is only available for Australia. Furthermore, the parent narrow product class "Data processing, hosting, and related services" is rarely available and the next parent broad product class "Information Services" is only available for a minority of countries (instead frequently being combined into "Computer programming, consultancy, and related services; Information Services").

Therefore, if the aim is to estimate the use of specific cloud-containing product classes, in almost all cases it will be necessary to begin with a broad aggregate and make estimations based on whatever information is available - and privileging the available use-side information as far as possible. Nevertheless, and as noted in section 4., the need to start estimation from very broad parent categories is likely to invite inaccuracy.

In an attempt to reflect this, a range of estimates has been developed, based on the different data presented throughout this paper. The starting point is the most widely available broad cloud-containing product class - "Computer programming, consultancy, and related services; Information Services". From this:

1. The Information Services portion can be estimated based on the use data available for 10 OECD countries, as presented in Table 7, with the mean of $23 \%$ and the Q1 and Q3 values of 13\% and 31\% used to reflect the variation in the shares observed.

2. Within this, the share of "Data processing, hosting, and related services" can be estimated based its average share for Canada in 2016-17 (33\%) and the share available for the United States in 2012 (66\%).

3. Finally, within that, the share of specific cloud-containing product classes can be:

a. Estimated based on their share in intermediate consumption of Information Services products in Australia which was stable across 2016 and 17 at 38\%, having grown sharply from a lower level of $13 \%$ over $2013-2014$ - with the mean share across the periods available (2013-17) being $25 \%$

b. Inferred using supply-side information: the 2012 information for the United States shown in Table $5(69 \%)$ and the average for Spain over 2016-2018, as shown in Figure $15(20 \%)$. Additionally, and bearing in mind the potential underestimation set out in the section above, the average cloud services share for Spain can be used directly $(5 \%)$.

It is important to be clear that this approach relies on several strong assumptions:

- That the shares for the countries available are likely to be representative of other countries. That is, the propensity of businesses in other countries to use "Information Services" and within that "Data processing, hosting, and related services" is similar to that observed in the countries for which information is available. This extends also to $3 \mathrm{a}$, where the share of specific cloud-containing products within intermediate consumption of Information Services in Australia would need to be assumed to be similar to that in other countries. 
- For 3b, in addition to assuming that the detailed product information available for Australia, Spain, and the United States is likely to be sufficiently relevant to businesses in other countries, it is also needed to assume that the share of specific cloud-containing products the supply of parent product categories in the countries for which data are available is also representative of their shares in use ${ }^{1}$.

Combining these parameters results in an array of factors with which to adjust "Computer programming, consultancy, and related services; Information Services", as set out in Table 8. This suggests that specific cloud-containing products comprise somewhere between roughly $1 \%$ and $14 \%$ of "Computer programming, consultancy and related services; Information Services", with the median average of these estimates being $5 \%$.

Table 8. Derived adjustment factors to estimate intermediate use specific cloud-containing products from "Computer programming, consultancy, and related services; Information Services"

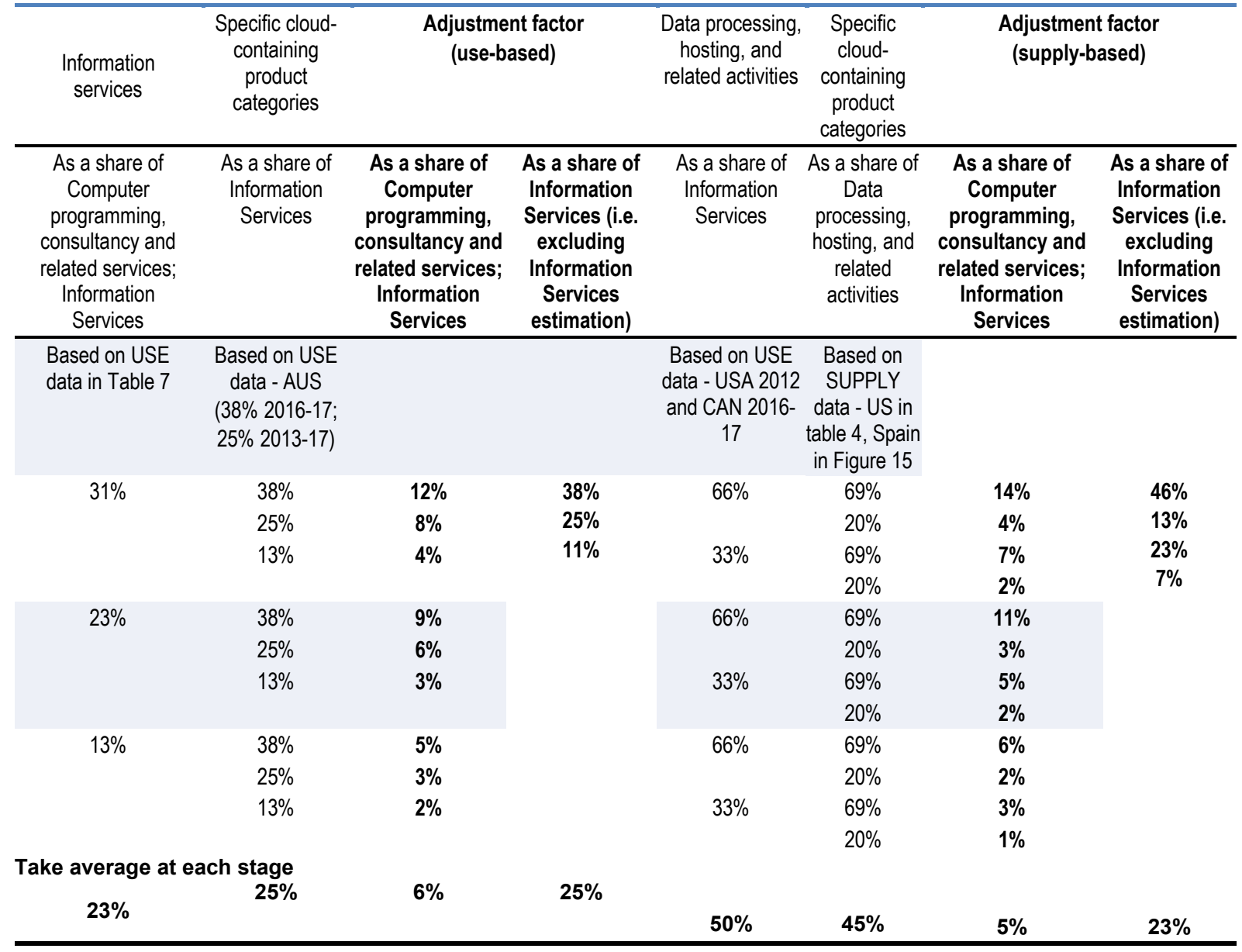

Source: OECD.

Figure 16 presents the range of the resulting estimates, along with median series to aid comparison. The range for estimates in which supply-side information is used to estimate the share of specific cloud-containing products in the parent product category is wider and with a lower median than for estimates based entirely on use-side information. 
For each country, the set of estimates varies widely. This reflects the uncertainty in the estimation process and the differing choices that can be made at each stage based on the data available, as set out in Table 8. The highest estimates resulting from all three stages of estimation (i.e. including estimation of Information Services) are around 14 times greater than the lowest. This large quantity and wide range in the estimates makes them challenging to use and interpret.

It should be noted that, when using supply-side information to derive estimates for the United States, the "best" estimate is the highest estimate of all available for the country. Unlike the other estimates, this is based entirely on US data:

- use of Information Services, as available from the supply-use tables

- the share of Data processing, hosting, and related services" observed from the 2012 US detailed supply-use tables (66\%), and

- the share of specific cloud containing products in US companies' revenues from sales of "Data processing, Internet publishing, and other information services" $(69 \%)$ as measured by the Economic census product line data (Table 5).

All the other figures are an underestimate compared to this, which illustrates the potential issues that can arise when applying shares observed in one country across others.

As a way through the wide range of estimates available, two series which will be used for further analysis are also presented in Figure 16:

1. The series based entirely on use-side information - taking the series based on the $38 \%$ share of specific cloud-containing products in intermediate consumption of Information Services as this share appears stable across the latest available periods (2016-17) and is markedly different from preceding periods.

a. For those countries for which "Information services" is available, that is used as the basis for estimation (38\%)

b. For other countries, "Computer programming, consultancy, and related services; Information Services" is used as the basis for estimation, with the average Information Services share being taken (i.e. $23 \% * 38 \%=9 \%$ ).

2. A series where use-side information is used to estimate the use of Data processing, hosting, and related activities products (a subset of Information Services) but supply-side information is used to estimate the share comprised by specific cloudcontaining products, combined as follows:

a. For the United States, the aforementioned "best estimate"

b. For those countries for which "Information services" is available, take that as the basis for estimation using the average from each relevant stage (i.e. $50 \% * 45 \%=23 \%$ )

c. For other countries, use "Computer programming, consultancy, and related services; Information Services" as the basis for estimation, coupled with average from each relevant stage (i.e. $23 \% * 50 \% * 45 \%=5 \%$ ). 
Figure 16. Estimated intermediate use of specific cloud-containing products, latest available year

USD million, current prices, purchasers' prices.

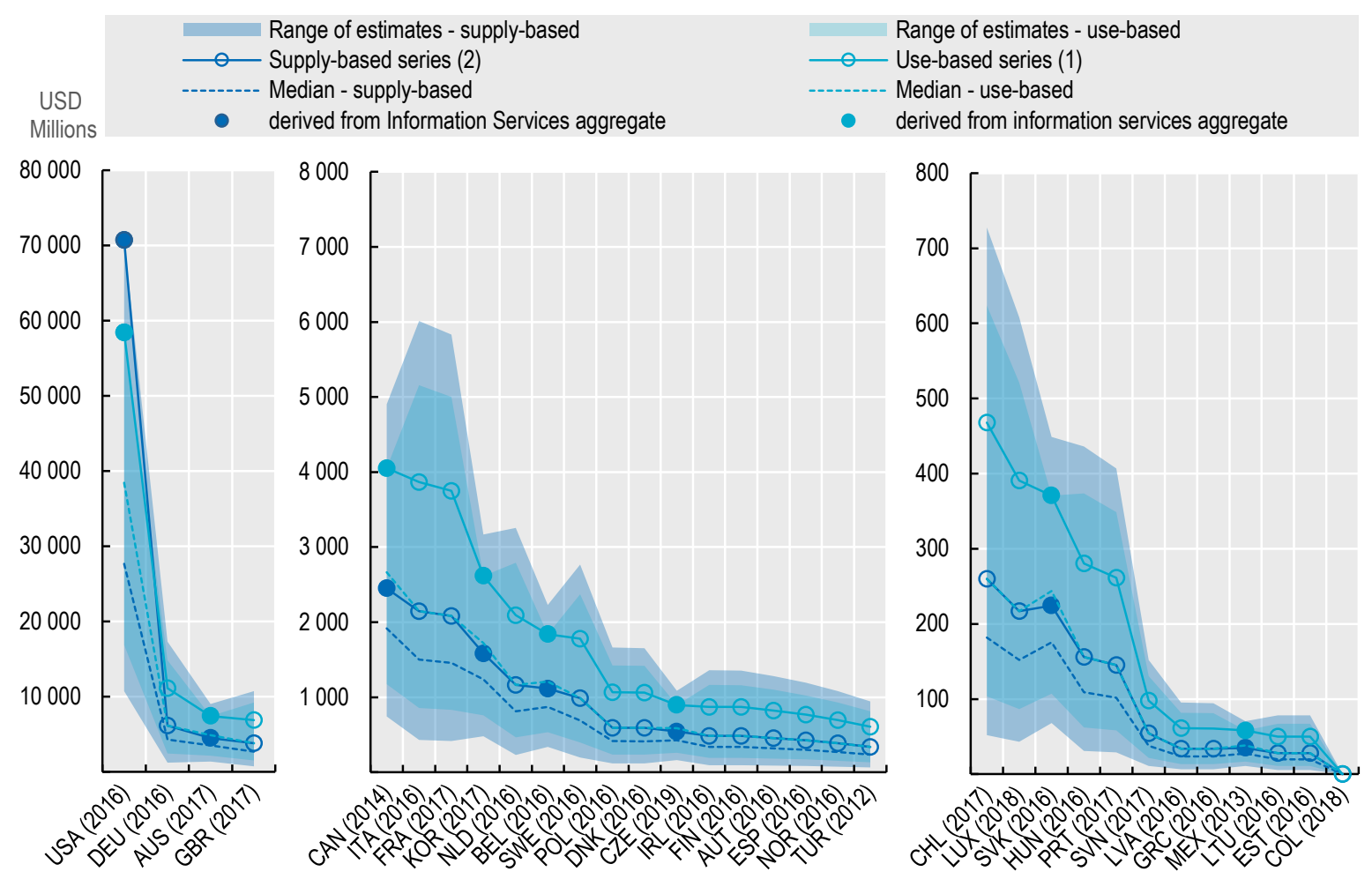

Source: OECD.

The estimates show that businesses in the United States appear to dwarf other countries in their overall spending on cloud services (as proxied by specific cloud-containing product classes). This may, at least partly, be driven by the sheer number of businesses there are in the USA. However, it is also possible that businesses in the United States have a higher propensity to use these products than those in other countries. This appears to be corroborated by the considerable difference in the portion which "Data processing, hosting, and related services" (narrow) comprises in "Information Services" (broad) in Canada and the US $-33 \%$ compared to $66 \%$. As such, using the US shares to derive estimates for other countries appears likely to result in over-estimation.

\section{Testing the estimates}

It is difficult to assess the validity of the absolute value of each of these estimates. Nevertheless, there are certain relationships that might be anticipated to exist and can be examined. For example, it might be expected that countries' business expenditure on specific cloud-containing products would be positively correlated with the share of firms in the country that report paying for cloud services on business ICT usage surveys. Table 9 presents correlation coefficients for these but finds that, across all estimates, the correlation is only loosely positive. However, when the estimates are split between those based on Information Services figures provided by the country - which require relatively less imputation - and those based on a broader starting aggregate a more nuanced picture 
appears. For the former, the correlation is fairly strong at $69 \%$ overall and up to $88 \%$ when looking at firms of particular sizes (number of employees).

Conversely, the results show effectively zero correlation between estimates based on the broader "Computer programming, consultancy, and related activities; Information Services" aggregate. This further suggests that estimates based on this aggregate are unlikely to be robust.

Table 9. Correlation between estimated intermediate use of specific cloud-containing products and businesses reporting paying for cloud services on ICT usage surveys

Correlation coefficients expressed as percentages.

\begin{tabular}{|c|c|c|c|c|c|c|c|c|c|c|}
\hline \multicolumn{11}{|c|}{ Correlation between estimated use of "specific cloud-containing products" and: } \\
\hline & \multicolumn{8}{|c|}{$\%$ of enterprises paying for cloud services } & \multirow{2}{*}{$\begin{array}{c}\text { Estimated } \\
\text { number of active } \\
\text { employer } \\
\text { enterprises } \\
\text { paying for cloud } \\
\text { services }\end{array}$} & \multirow[b]{2}{*}{$\begin{array}{r}\text { No. of } \\
\text { countries }\end{array}$} \\
\hline & All & $\begin{array}{r}\text { No. of } \\
\text { countries }\end{array}$ & Large & $\begin{array}{r}\text { No. of } \\
\text { countries }\end{array}$ & Medium & $\begin{array}{r}\text { No. of } \\
\text { countries }\end{array}$ & Small & $\begin{array}{r}\text { No. of } \\
\text { countries }\end{array}$ & & \\
\hline \multicolumn{11}{|l|}{$\begin{array}{l}\text { Use-based } \\
\text { estimates }\end{array}$} \\
\hline All estimates & $39 \%$ & 30 & $18 \%$ & 29 & $16 \%$ & 29 & $24 \%$ & 29 & $63 \%$ & $27^{*}$ \\
\hline $\begin{array}{l}\text { Estimates based on } \\
\text { Information Services }\end{array}$ & $69 \%$ & 8 & $66 \%$ & 7 & $79 \%$ & 7 & $88 \%$ & 7 & $95 \%$ & $5^{*}$ \\
\hline $\begin{array}{l}\text { Estimates based on } \\
\text { "Computer } \\
\text { programming, } \\
\text { consultancy, and } \\
\text { related services; } \\
\text { Information Services" }\end{array}$ & $6 \%$ & 22 & $6 \%$ & 22 & $2 \%$ & 22 & $7 \%$ & 22 & $61 \%$ & 22 \\
\hline \multicolumn{11}{|l|}{$\begin{array}{l}\text { Supply-based } \\
\text { estimates }\end{array}$} \\
\hline All estimates & $37 \%$ & 30 & $18 \%$ & 29 & $17 \%$ & 29 & $25 \%$ & 29 & $64 \%$ & $27^{\star}$ \\
\hline $\begin{array}{l}\text { Estimates based on } \\
\text { Information Services }\end{array}$ & $65 \%$ & 8 & $66 \%$ & 7 & $79 \%$ & 7 & $88 \%$ & 7 & $95 \%$ & $5^{*}$ \\
\hline $\begin{array}{l}\text { Estimates based on } \\
\text { "Computer } \\
\text { programming, } \\
\text { consultancy, and } \\
\text { related services; } \\
\text { Information Services" }\end{array}$ & $6 \%$ & 22 & $6 \%$ & 22 & $2 \%$ & 22 & $7 \%$ & 22 & $61 \%$ & 22 \\
\hline
\end{tabular}

Note: * Population of active employer enterprises unavailable for AUS, USA, MEX, which are therefore excluded from the analysis. Based on the number of active employer enterprises in ISIC rev.4 sectors 05_82_LESS_642: Total industry, construction and market services except holding companies.

This table presents estimates derived from data from multiple sources. In particular, use of "Information Services" or otherwise "Computer programming, consultancy and related services; Information services" from the OECD supply-use database, businesses purchasing cloud computing services from the OECD ICT Access and Usage by Business Database, and the number of active employer enterprises from the OECD Structural Business Demography Statistics Database. For each country the years available in each database vary. As far as possible, components from the same year were used in the estimation for each country. Where necessary, compomnents from the closest available year were used.

Source: OECD based on OECD supply-use database, OECD business ICT usage database, OECD structural business demography statistics database, and national sources.

By coupling the information from business ICT usage surveys with figures on the numbers of "active employer enterprises in each country" from the OECD Structural Business Demography Statistics database, the number of businesses paying for cloud services can 
be estimated. As shown in Table 9, this exhibits a much stronger positive correlation of over $60 \%$ overall. However, unfortunately the database does not host these figures for Australia, Mexico, or the United States and as such they are excluded from the analysis.

Figure 17 presents a scatterplot of these two series, with Germany and the United Kingdom particularly standing out. The former spends considerably more on specific cloudcontaining product categories than other countries with a similar estimated number of businesses that purchase cloud services (e.g. France, Spain). Meanwhile, the United Kingdom has a much higher overall number of firms estimated to purchase cloud services - largely due to having considerably more businesses than the other countries assessed (2.3 million businesses compared to 1.5 million in Germany, and 1.1-1.4 million in Italy, Spain and France).

Figure 17. Estimated business use of specific cloud-containing products (USD millions) and the estimated number of active employer enterprises paying for cloud services (thousands)

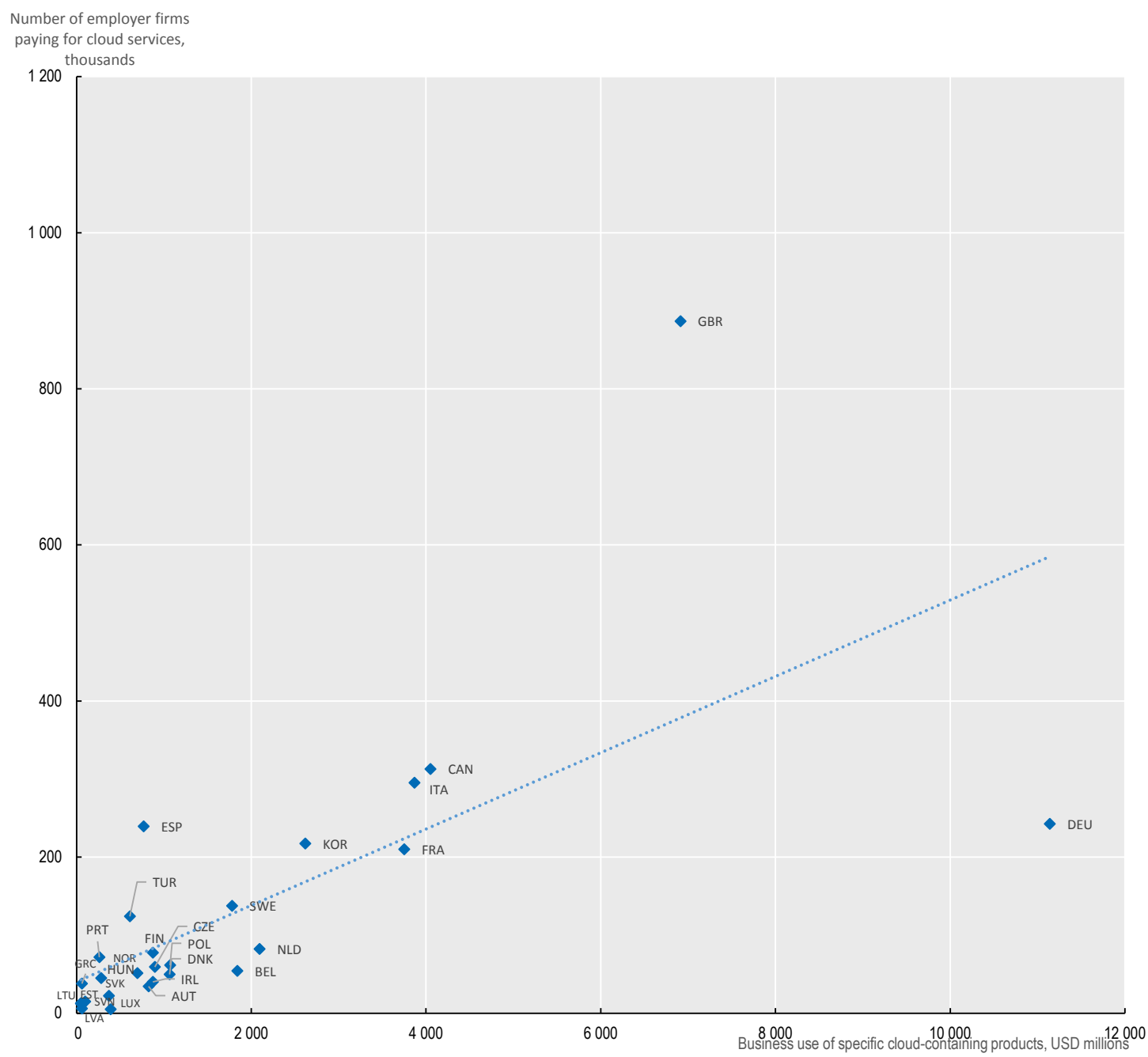

Note: Based on the number of active employer enterprises in ISIC rev.4 sectors 05_82_LESS_642: Total industry, construction and market services except holding companies. Population of active employer enterprises unavailable for AUS, USA, MEX, which are therefore excluded from this analysis.

Source: OECD based on OECD supply-use database, OECD business ICT usage database, OECD structural business demography statistics database, and national sources. 
A natural extension to this is to calculate the average expenditure per business on specific cloud-containing product classes as implied by these estimates. Figure 18 shows that firms in Luxembourg appear to spend markedly more than others on specific cloud-containing product categories at around 78000 USD annually. This may be influenced by the relative prevalence of large, multinational firms in Luxembourg - with large firms being the most likely to use cloud services $\left(\mathrm{OECD}, 2019_{[1]}\right)$ and being likely to spend more than other firms (e.g. because they have more users for services charged on a per-user basis). Germany and Belgium follow up at around 35-45 000 USD. Meanwhile, the United Kingdom appears to have the lowest average business spend on cloud-containing products of the G7 countries shown, at just below 8000 USD (although it should be considered that estimates are not possible for the USA or Japan).

The primary focus is on the "use-based" estimates, as the main focus is on business' use of specific cloud-containing products and the "use-based" estimates are based on the reported share of these products in business' intermediate consumption (in Australia). By comparison the estimates which use supply-side information from the USA and Canada to infer the share of these products are routinely lower - at around half the value.

Figure 18. Estimated average expenditure on cloud services per active employer enterprise, latest available year

USD, purchasers' prices, current prices

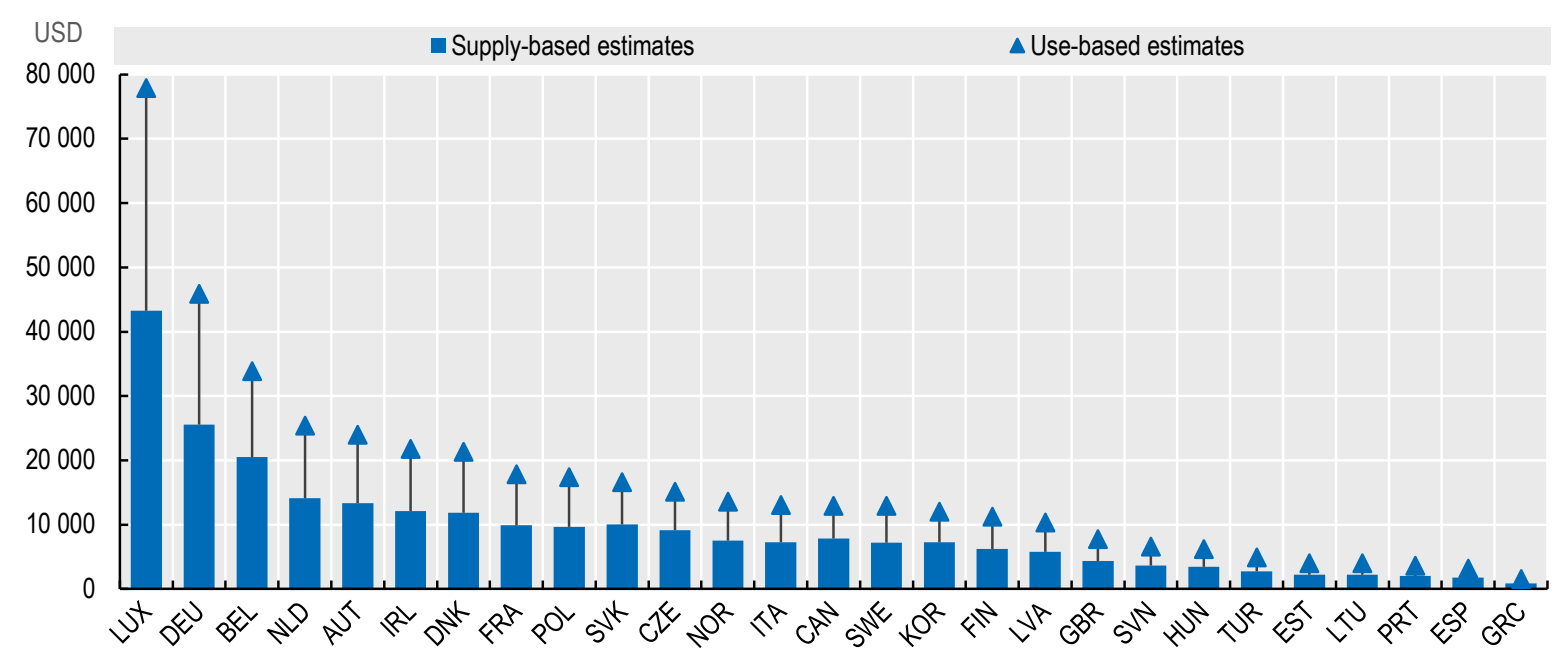

Note: Based on the number of active employer enterprises in ISIC rev.4 sectors 05_82_LESS_642: Total industry, construction and market services except holding companies. Population of active employer enterprises unavailable for AUS, USA, MEX, which are therefore excluded from this analysis.

Source: OECD based on OECD supply-use database, OECD business ICT usage database, OECD structural business demography statistics database, and national sources.

\section{Estimates over time}

In addition to looking at the panel of the latest estimates available for each country, it is relevant to consider how business' use of specific cloud containing product classes has changed over time. Figure 19 presents nominal annual average growth rates over the years 
available for each country, finding high rates of annual growth in countries such as Lithuania $(+140 \%$ annual average growth), Estonia, Sweden (both $+120 \%)$, and The Netherlands, Poland, and Luxembourg $(+100 \%)$. Australia - the only country for which full detail on the use of specific cloud-containing products is available - shows a higher annual average growth than is estimated for other countries. The availability of equivalent data detail from other countries would greatly improve our ability to understand the patterns of use of specific cloud-containing products across countries.

Ireland and Spain exhibit the lowest annual average growth in the use of specific cloudcontaining products at around $+30 \%$ over the period available (2013-2016) - with the estimate being pulled down by declines in the estimation base for these countries ("Computer programming, consultancy and related services; Information services").

\section{Figure 19. Nominal annual average growth rate of business use of specific cloud containing product classes, 2013-latest}

Showing contributions to the estimated change

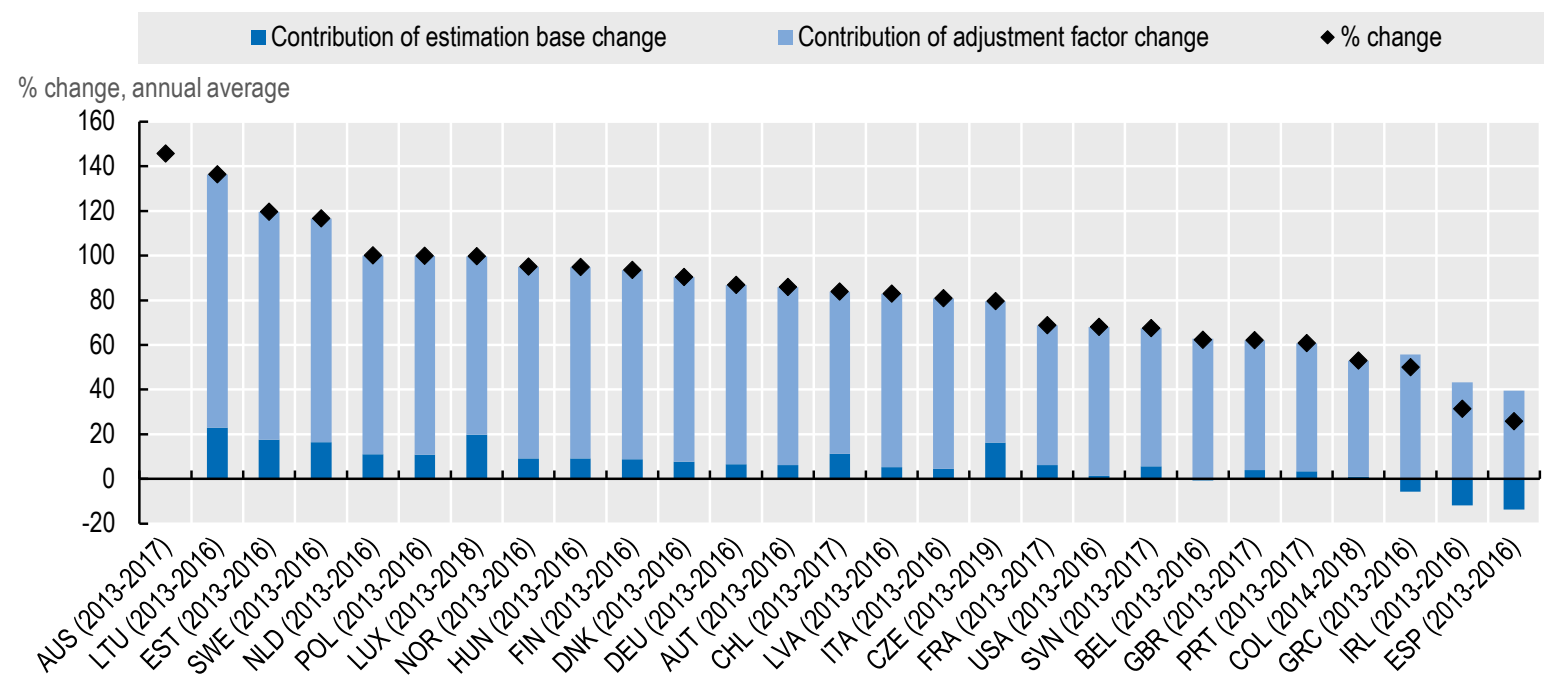

Note: "Annual average growth rates" are derived by calculating the percentage change in the estimated use of specific cloud-containing products between the first and latest periods available for each country (shown in brackets) and dividing the result by the number of years covered. Calculated using figures in national currency to avoid distortions from exchamge rate fluctuations. The figure for Australia is calculated directly from the provided expenditure on specific cloud-containing products with no estimation necessary.

"Estimation base" refers to the aggregate the estimate is derived from i.e. "Information Services" when available, otherwise "Computer programming, consultancy and related services; Information services".

"Contribution of estimation base change" referrs to the portion of the change arising from a difference in the estimation base between the earliest and latest years available for each country. The contribution is negative when the estimation base has decreased.

"Adjustment factor" refers to the share used to estimate the portion of the estimation base that relates to specific cloud-containing products.

To produce the time-series of use of specific cloud-containing products from which these changes are estimated, the use-based factors were used. For the latest year available for each country, a factor of $38 \%$ of Information Services, based on the share for AUS shown in Table 8 is used (or $23 \% * 38 \%=9 \%$ of "Computer programming, consultancy and related services; Information services" when necessary). For the earlier year available for each country, a use-based factor of $13 \%$ is used - based on the average share of specific cloudcontaining products in Information Services for AUS over 2013-14 (or 23\%*13\%=3\% of "Computer programming, consultancy and related services; Information services" when necessary). As such, where Information Services estimation is necessary the factor used does not vary over time (23\%). Countries where data only provide for a gap of one or two years are excluded. 
Source: OECD based on OECD supply-use database and national sources.

Growth (or decline) in the estimation base (i.e. Information Services when available, otherwise Computer programming, consultancy, and related services; Information Services) is one source of change in the estimates over time. These higher level changes may be driven by increasing uptake of cloud services, but will also reflect other factors such as uptake (or decline in use) of the other products they cover.

The other source is the marked increase in the share of specific cloud-containing products in business intermediate consumption in Australia - from an average of 13\% over 2013-14 to a stable level of $38 \%$ in 2016 and 2017. As a result the adjustment factor applied to the "latest" observation available for each country is greater than for the earliest and this contributes the majority of the growth seen.

These estimates concord with the cloud services experiencing broadening uptake amongst businesses (OECD, 2019 $\left.{ }_{[1]}\right)$. Furthermore, it should be noted that no account has been made for price changes - which are likely to strongly affect the uptake of cloud services. Prices for cloud services are likely to be falling rapidly, especially when key factors such as speed and storage volume are considered (Coyle and Nguyen, 2019 $\left.{ }_{[18]}\right)$. However, they pose an additional measurement challenge, as briefly discussed in the following section.

Like the other data discussed in previous section, price indices for cloud services - or for specific cloud-containing products - are hard to come by. Most European statistical system countries compile Services Producer Price Indices for "Information Service Activities", as shown in Figure 20. These indices vary widely in trajectory between countries, with some reporting steep price increases while others show sharp price declines. On average across the EU, the result is an index that has risen gently from 99 in 2012 to 105 in 2019. Fourteen of these EU countries also publish a lower-level index for "Data processing, hosting and related activities; web portals", though this generally exhibits the same trends as the parent index (Figure 21). Unfortunately, though, there are not enough countries to be able to produce a summary index for the EU as a whole at that level. 
Figure 20. Information Service Activities, total output price index, European countries $2012-2019,2015=100$

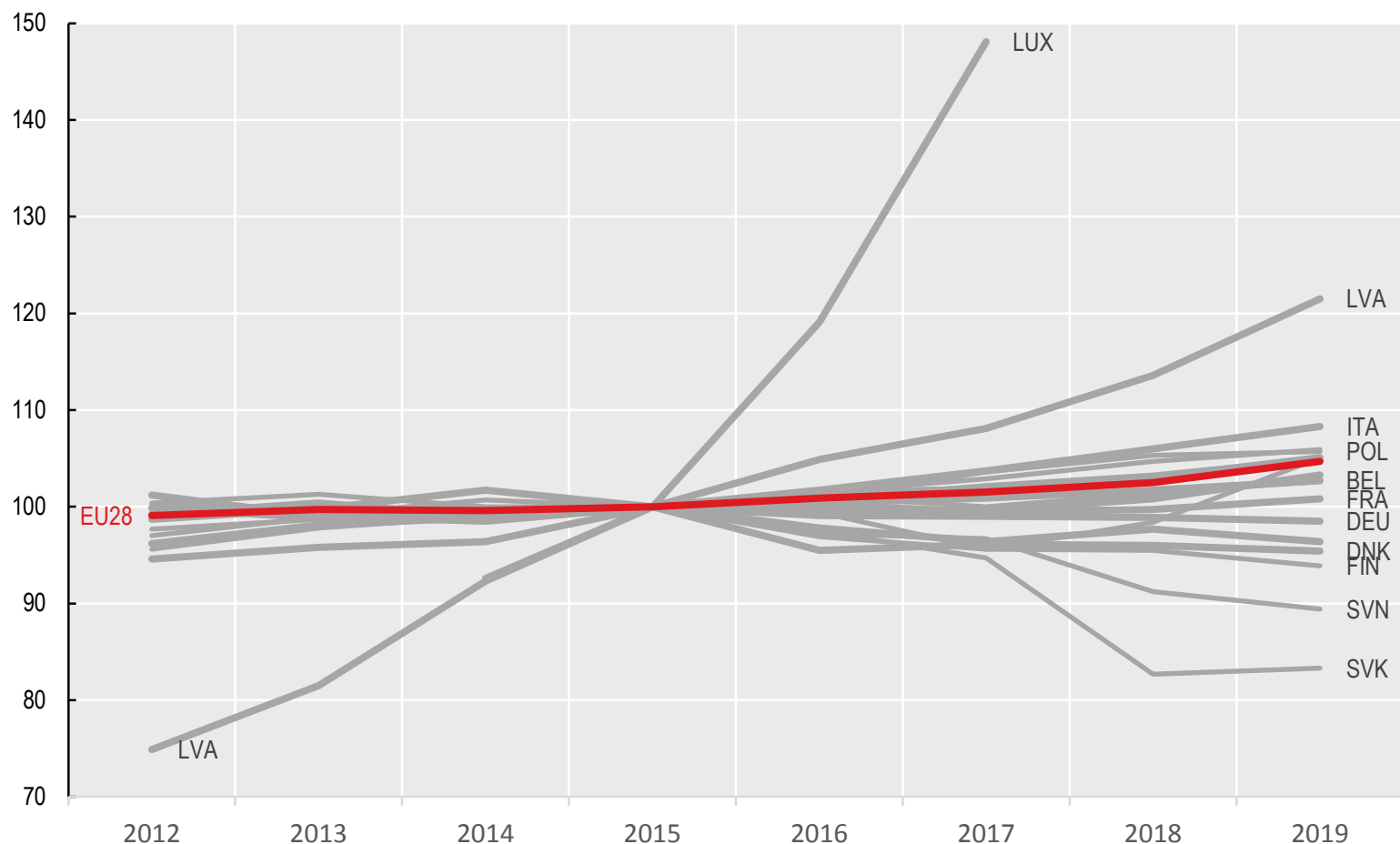

Note: Based on unadjusted data (i.e. neither seasonally adjusted nor calendar adjusted data) in national currency. Source: OECD based on Eurostat Service producer prices - annual data, August 2020.

Figure 21. Data processing, hosting and related activities; web portals, total output price index, European countries

$$
2012-2019,2015=100
$$

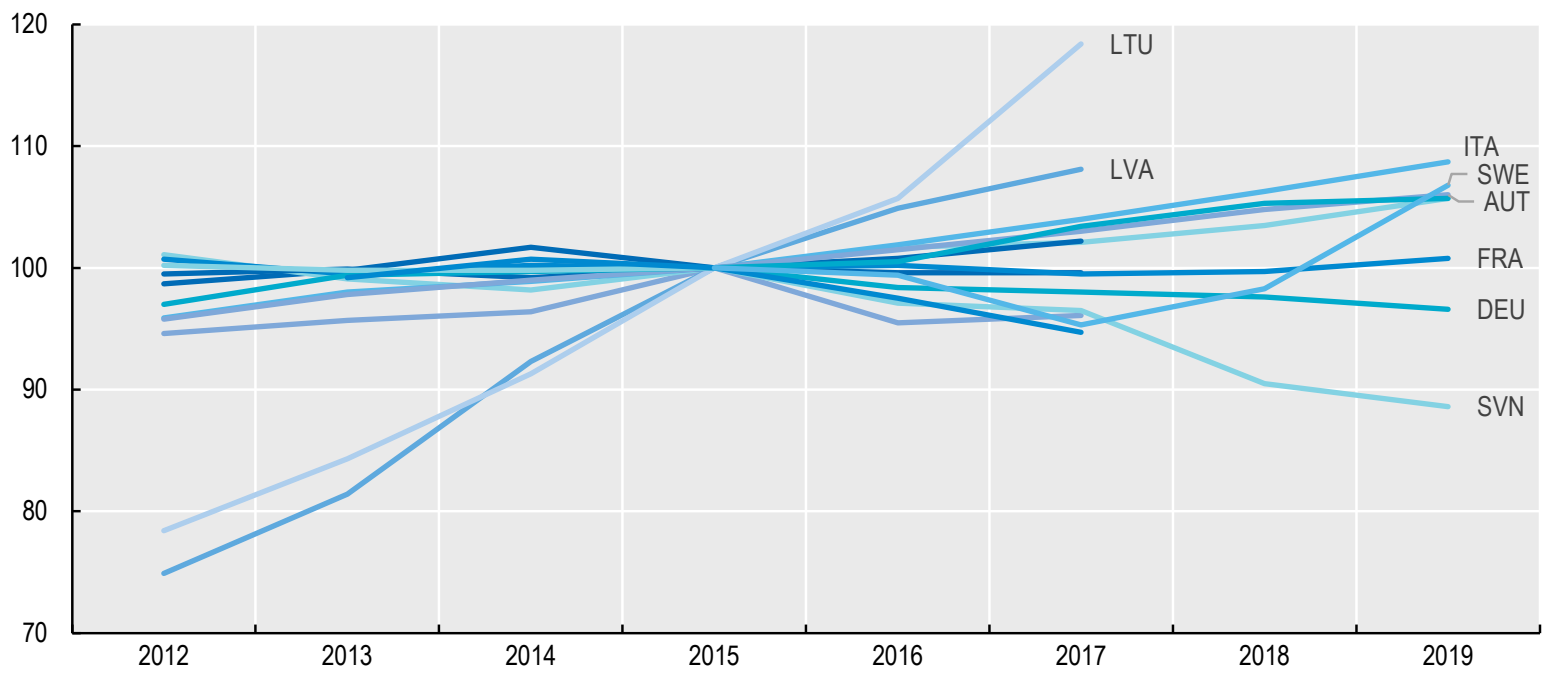

Note: Based on unadjusted data (i.e. neither seasonally adjusted nor calendar adjusted data) in national currency. Source: OECD based on Eurostat Service producer prices - annual data, August 2020. 
For the United States, an even more specific producer price index is available, this covers "hosting, application service provisioning, and other IT infrastructure provisioning services" (Figure 22). It shows a similar upward trend, increasing from 99 in 2012 to 106 at the end of 2019.

Figure 22. Producer price index: hosting, application service provisioning and other IT infrastructure provisioning services, United States

2012-2019

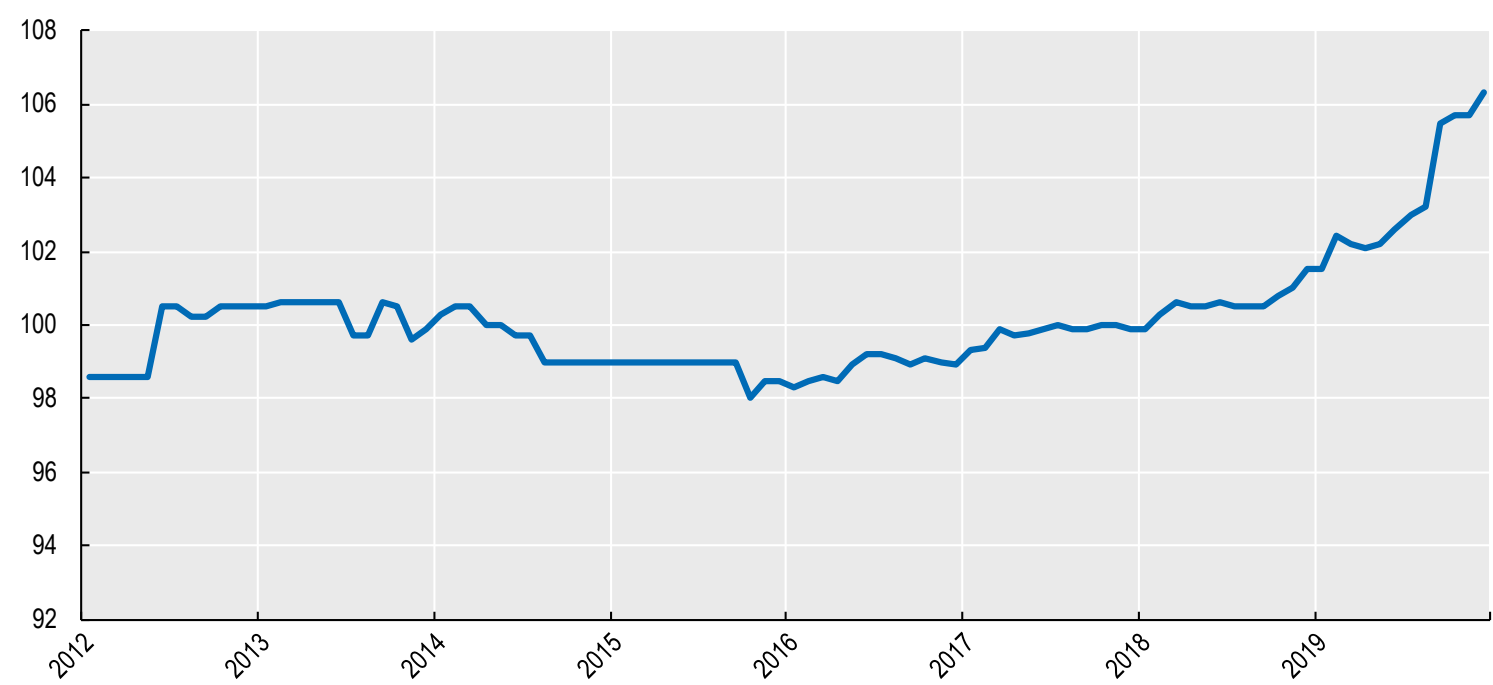

Note: Not Seasonally Adjusted

Source: US Bureau of Labor Statistics, August 2020.

However, there is some question about how well these indices are accounting for price changes in cloud services - and especially for increases in processing power, storage, and features that can be accessed for a given price. Suitably accouting for such complex and rapid developments which are a key feature of digital technologies is a known area of considerable measurement challenge (see for instance Byrne and Corrado $\left(2017_{[19]}\right)$. To examine this, Coyle and Nguyen $\left(2019_{[18]}\right)$ used archived prices for key $\mathrm{AWS}^{2}$ services to develop price indices for AWS services of varying "instance classes" ("small" to "24Xlarge") covering both Windows and Linux operating systems. They find prices have markedly decreased over time - and even more so when sequential upgrades in processing power are factored in. Figure $\mathbf{2 3}$ gives an illustrative example in which prices declined by over two-thirds between 2010 and 2019. They conclude that "quality-adjusted prices of cloud services have been falling rapidly over the past decade, [and this is] is currently not captured by the deflators used in official statistics". 
Figure 23. Price index (nominal and quality-adjusted) for AWS General Purpose EC2 xlarge Linux instance, 2010Q1-2019Q3

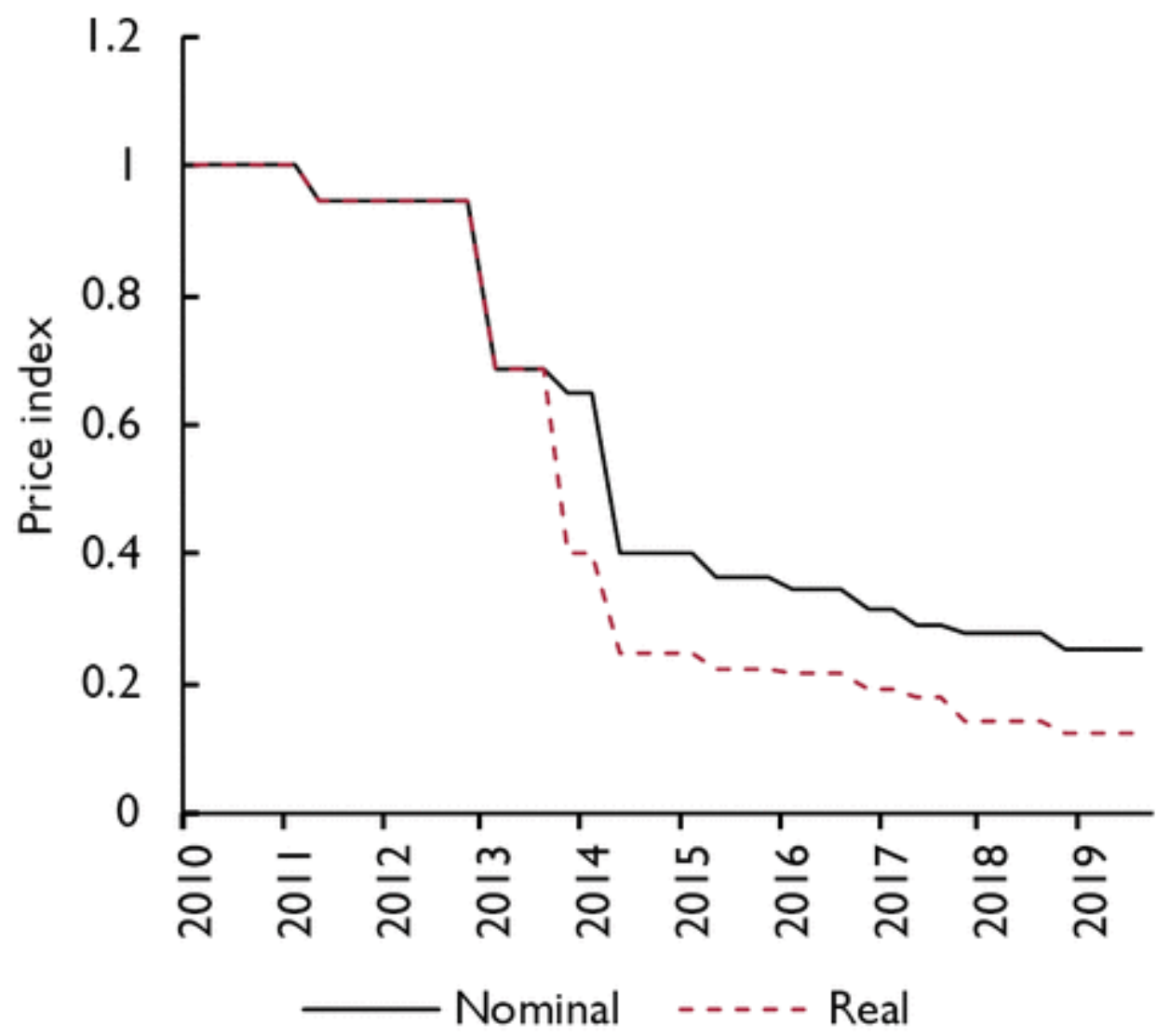

Note: "Real" refers to the quality adjusted series.

Source: (Coyle and Nguyen, 2019[18])

It can be summarised, then, that prices are another area where key measurement challenges must be overcome in order to gain real and robust insights into cloud services expenditure by businesses. This matter is beyond the scope of this paper. Nevertheless, it is important to bear in mind that whether prices are increasing or decreasing have different implications for the growth of cloud services over time. Increasing prices imply a suppression of the growth estimated in Figure 19, whereas rapidly falling prices would imply even more rapid uptake as businesses mainstream cloud services into their ICT infrastructure. 


\section{Conclusions and further work}

Product classification systems offer differing abilities to focus in on cloud services products. Only the Japanese services product classification systematically delineates cloud services specifically (IaaS, PaaS, SaaS). In other cases, it is necessary to identify specific cloud-containing product categories. Furthermore, while the CPC, CPA, and NAPCS appear to offer some degree of cross-compatibility, their differences, coupled with differences in the way products are aggregated for publication can create challenges.

The level of detail available in published data sources is also a significant challenge. Use tables, a natural starting point when considering business expenditures on certain products, typically provide only broad or narrow cloud-containing product categories.

It is therefore necessary to seek sources offering more detailed disaggregation. Unfortunately, limited use-side sources have been found so far. The most detailed data discovered are 2012 US Economic Census product line data, which can be used to estimate the share of specific cloud-containing product categories in narrow and broad parent category totals and additional data provided by Spain.

It is possible to then apply these shares to the use side. However, this approach requires strong assumptions that may be especially likely to break down at the industry level or over time. The 2017 US Economic Census and detailed supply-use tables, due out in 2021, will provide useful additional data once available.

Nevertheless, the above are supply-side measures and the main focus (business expenditure on cloud services) is a use-side phenomenon. Data provided by Australia provide an indication of the share of specific cloud-containing products in business intermediate consumption. Estimates using both supply- and use-side data have been produced and compared, with the former having a wider range but generally resulting in lower estimates on average.

Likewise, the approach can be applied across countries, though that requires even stronger assumptions.

This paper has developed a set of estimates of business use of specific cloud-containing product classes covering most OECD countries. Although these have clear limitations, and the assumptions underpinning them are certainly open to challenge, the fairly strong positive correlation between these and the estimated number of firms paying for cloud services in each country provides at least some reassurance.

Nevertheless, the over-arching conclusion is that, if we are to gain real insights into the role that cloud services are playing in our economies, there is a strong need to design and implement collections of the relevant data. One step in the right direction would be to collect more detail around the specific cloud-containing product classes identified in this paper. However, even that is only likely to get us incrementally closer to measuring business use of cloud services. Ultimately, there is a need to develop ways to collect data that accurately delineates between services underpinned by cloud architectures, and similar services (which may essentially be identical from the using business' perspective but which do not implement cloud architectures and should hence be recorded elsewhere). Efforts by countries such as Japan, Korea, Spain and Canada have started to move in this direction. Nevertheless, significant further effort will be needed to gain meaningful understanding of how cloud services are powering business. 


\section{References}

ABS (2001), The demise of ANZSPC as the Australian statistical standard for products, https://www.abs.gov.au/ausstats/abs@.nsf/mf/1254.0.55.001.

AWS (2019), Netflix on AWS, https://aws.amazon.com/solutions/case-studies/netflix/.

Byrne, D. and C. Corrado (2017), ICT Prices and ICT Services: What do they tell us about Productivity and Technology?, https://doi.org/10.17016/FEDS.2017.015.

Coyle, D. and D. Nguyen (2019), Cloud Computing, Cross-Border Data Flows and New Challenges for Measurement in Economics, https://doi.org/10.1177/002795011924900112.

Dignan, L. (2019), Enterprise software vendors mix and match monetization models: What happens when subscription, usage and licensing converge?, https://www.zdnet.com/article/enterprise-software-cloud-vendors-likely-to-mixmonetization-models-what-happens-when-subscription-usage-and-licensing-converge/.

Dignan, L. (2019a), Top cloud providers 2019: AWS, Microsoft Azure, Google Cloud; IBM makes hybrid move; Salesforce dominates SaaS, https://www.zdnet.com/article/top-cloudproviders-2019-aws-microsoft-azure-google-cloud-ibm-makes-hybrid-move-salesforcedominates-saas/.

Eurostat (2018), Task Force Price and Volume Measures for Services Activities: Final Report, https://unstats.un.org/unsd/nationalaccount/aeg/2018/M12_3b_Price_Volume_Services_Acti vities.pdf.

Eurostat (2015), CPA Ver. 2.1 Structure and explanatory notes, http://webarchive.nationalarchives.gov.uk/20160105160709/http://www.ons.gov.uk/ons/guid e-method/classifications/other-classifications-used-within-national-statistics/other-nationaland-international-classifications/cpa-ver--2-1-structure-and-explanatory-n.

Gartner (2019), Gartner Says Worldwide IaaS Public Cloud Services Market Grew 31.3\% in 2018, https:/www.gartner.com/en/newsroom/press-releases/2019-07-29-gartner-saysworldwide-iaas-public-cloud-services-market-grew-31 point3-percent-in-2018.

INEGI (n.d.), SICPAN - NAPCS - SCPAN, http://naics-scian.inegi.org.mx/SICPAN/default.aspx.

Jung, K., Y. Cho and Y. Tak (2017), Performance evaluation of ROMS v3.6 on a commercial cloud system, https://doi.org/10.5194/gmd-2017-270.

Mell, P. and T. Grance (2011), The NIST Definition of Cloud Computing, https://nvlpubs.nist.gov/nistpubs/Legacy/SP/nistspecialpublication800-145.pdf.

MIC (2019), Product classification in the service sector, http://www.soumu.go.jp/toukei toukatsu/index/seido/service/index.htm. 
OECD (2019), Measuring the Digital Transformation: A Roadmap for the Future, OECD

Publishing, Paris, https://dx.doi.org/10.1787/9789264311992-en.

OECD (2017), OECD Science, Technology and Industry Scoreboard 2017: The digital transformation, OECD Publishing, Paris, https://dx.doi.org/10.1787/9789264268821-en.

OECD (2014), Cloud Computing: The Concept, Impacts and the Role of Government Policy, http://dx.doi.org/DSTI/ICCP(2011)19/FINAL.

Statistics Canada (2018), North American Product Classification System (NAPCS) Canada 2017 Version 2.0, https://www.statcan.gc.ca/eng/subjects/standard/napcs/2017v2/index.

Tag, S. and A. Pitkanen (2018), Data Processing, Hosting, and Related Activities (ISIC 6311) with emphasisi on cloud computing, https://www.voorburggroup.org/Documents/2018\%20Rome/Papers/1016.pdf.

United Nations, Statistics Division (2015), Central Product Classification (CPC) Version 2.1, https://unstats.un.org/unsd/classifications/unsdclassifications/cpcv21.pdf.

US Census Bureau (2019), 2017 NAPCS-Based Collection Code to 2012 Product Code, https://www.census.gov/programs-surveys/economic-census/guidance/understandingnapcs.html.

US Census Bureau (n.d.), North American Product Classification System, https://www.census.gov/eos/www/napcs/more.html. 


\section{Notes}

${ }^{1}$ This may or may not feed through to the amounts users are charged. Although pay-per-use is one key model, subscriptions allowing "all you can eat" use are also common. Furthermore, there is an emerging trend towards "blended" models combining features of subscription, usage, and licencingbased charging (Dignan, 2019 [20]).

${ }^{2}$ CPC class 73 "leasing or rental services without operator", within which subclass "733 Licensing services for the right to use intellectual property products and similar products" covers "permitting, granting, or otherwise authorising" the use of such products, which would include software. "Leased" can therefore be read as a synonym of "licenced". As such, it could be that, in order to be included in subclass 83152, the software concerned cannot be owned outright by the cloud service vendor but instead must be licenced from a third party. If that is the case, as an example, a product in which a cloud infrastructure is used to offer Microsoft Office to consumers would be recorded in this category - unless the vendor of that product is Microsoft itself (which owns rather than licenses the software).

${ }^{3}$ Furthermore, streaming services are often perhaps best characterised as major cloud services customers rather than cloud service providers themselves. For example, Netflix has migrated its entire business to the AWS cloud; resource pooling and rapid elasticity allows Netflix to provide consistent service to its customers, but "rapid elasticity" is not really relevant to those customers themselves, who typically watch only one video at a time (AWS, 2019[21]).

${ }^{1}$ This will be the case at the global level but could well vary between countries. Nevertheless, as the detailed supply-use tables for the United States suggest that the vast majority (over 99\%) of "data processing, hosting, and related services" consumed by US businesses are produced domestically, this suggests that the assumption needed essentially equates to assuming that companies in other countries have the same propensity to use cloud-containing products as those in the United States.

${ }^{2}$ Amazon Web Services, the largest public cloud provider globally. 